\title{
HYBRID ROCKET BURNING RATE ENHANCEMENT BY NANO-SCALE ADDITIVES IN HTPB FUEL GRAINS
}

\author{
A Thesis \\ by \\ JAMES C THOMAS
Submitted to the Office of Graduate and Professional Studies of Texas A\&M University in partial fulfillment of the requirements for the degree of
MASTER OF SCIENCE

\begin{abstract}
Chair of Committee, Eric L Petersen
Committee Members, Partha P Mukherjee

Adonios N Karpetis

Head of Department, Andreas A Polycarpou
\end{abstract}

December 2014

Major Subject: Mechanical Engineering

Copyright 2014 James C Thomas 


\begin{abstract}
Low regression rates in hybrid rockets limit their use and capability, but additive aluminum nano-particles represent a possible solution to this problem. In this thesis, aluminum nano-particles were characterized and added to hybrid motor grains to assess their effects on the combustion behavior of hybrid rocket fuel grains. Procedures for the fabrication of 6-inch-long motors with combustion port diameters of $1 \mathrm{~cm}$ and $2.54 \mathrm{~cm}$ (1 inch) were developed for formulations with and without additive particles. The implementation of commercial aluminum particles at a mass loading of 5\% as a burning rate enhancer was assessed on a lab-scale burner. Traditional temporally and spatially averaged techniques were applied to determine the regression rates of plain and aluminized HTPB motors burning in gaseous oxygen. Resistance-based regression sensors were embedded in motor grains and used to determine instantaneous and averaged burning rates. The resistive-based sensors exhibited good accuracy and unique capabilities not achievable with other regression measurement techniques, but still have limitations. The addition of commercial nano-aluminum, with a diameter of $100 \mathrm{~nm}$, to hybrid motors increased the motor surface regression rate for oxidizer mass fluxes in the range of $0-15 \mathrm{~g} / \mathrm{cm}^{2}$-s. Future testing will focus on the evaluation of motors containing novel aluminum particles manufactured in situ with the HTPB at a mass loading of 5\%, which are expected to perform better than similar commercially aluminized motors.
\end{abstract}




\section{ACKNOWLEDGMENTS}

The research presented in this thesis is the culmination of many years of hard work and would not have been successful without the contributions of many people. Andrew Demko, Thomas Sammet, and Ray Matthews, all of Texas A\&M University, were instrumental in developing the motor manufacturing methods and procedures described herein. John DeSain and Brian Brady, both of the Aerospace Corporation, were active in developing testing procedures and responsible for carrying out burning rate testing. Dr. David Reid and Dr. Sudipta Seal, both of the University of Central Florida, were responsible for the development of manufacturing procedures of the described novel aluminum and were contributory in characterizing it. The contributions of all of these people to this project have been invaluable.

Dr. Eric L. Petersen, of Texas A\&M University, has served as my research advisor and mentor since I was accepted into the Propulsion Laboratory in 2011. Working under Dr. Petersen has been more than an opportunity, but a privilege in itself. His dedication to his research, work, teaching, and advising is unparalleled by any professor or industry member I have met to date. I have learned more from him in the last few years than I could have ever imagined and look forward to continuing my education under his guidance at Texas A\&M University.

Dr. Partha Mukherjee and Dr. Adonios Karpetis have both taught classes I have enrolled in and were selected as committee members for their dedication to their 
teaching, their past experience with systems related to this research project, and for the excitement and enthusiasm they brought to the classroom.

This work at the Aerospace Corporation was supported under The Aerospace Corporation's Sustained Experimentation and Research for Program Applications. Funding for the Texas A\&M University and University of Central Florida efforts came primarily from NSF projects EEC-1004859 and EEC-1263196. 


\section{NOMENCLATURE}

$\begin{array}{ll}\text { ACAC } & \text { Acetylacetone } \\ \bar{A}_{c} & \text { Average Combustion Port Cross-Sectional Area } \\ a & \text { Empirical Constant } \\ b & \text { Empirical Constant } \\ \text { DOA } & \text { Dioctyl Adipate } \\ \bar{D} & \text { Average Combustion Port Diameter } \\ D_{i} & \text { Initial Combustion Port Diameter } \\ D_{f} & \text { Final Combustion Port Diameter } \\ \text { EDX } & \text { Energy Dispersive X-ray Spectroscopy } \\ \text { EEW } & \text { Electrical Explosion of Wire } \\ \text { EFTEM } & \text { Energy-Filtered Transmission Electron Microscopy } \\ \text { FFT } & \text { Fast Fourier Transform } \\ f_{b} & \text { Resistor Burn-Off Frequency } \\ G_{o x} & \text { Oxidizer Mass Flux } \\ \text { HTPB } & \text { Hydroxyl-Terminated-Polybutadiene } \\ \text { IPDI } & \text { Isophorone Diisocyanate } \\ M & \text { Oxidizer Molecular Weight } \\ m & \text { Empirical Constant } \\ \text { MDI } & \text { Miniature Resistive Regression and Ablation Sensor } \\ \text { MIRRAS } & \end{array}$




\begin{tabular}{|c|c|}
\hline$\Delta m$ & Change in Motor mass \\
\hline$m_{i}$ & Initial Motor Mass \\
\hline$m_{f}$ & Final Motor Mass \\
\hline$\dot{m}$ & Motor Mass-Loss Rate \\
\hline$\dot{m}_{o x}$ & Oxidizer Mass Flow Rate \\
\hline$\Delta m_{o x}$ & Change in Mass of Oxidizer in Tank \\
\hline$n$ & Empirical Constant \\
\hline$P_{i}$ & Initial Oxidizer Tank Pressure \\
\hline$P_{f}$ & Final Oxidizer Tank Pressure \\
\hline$R$ & Regression Sensor Resolution \\
\hline $\bar{R}$ & Universal Gas Constant \\
\hline$r$ & Regression Rate \\
\hline $\bar{r}_{b}$ & Average Regression Rate \\
\hline SEM & Scanning Electron Microscopy \\
\hline$T$ & Temperature of Oxidizer Tank \\
\hline TAMU & Texas A\&M University \\
\hline TEM & Transmission Electron Microscopy \\
\hline TOT & Thickness over Time Technique \\
\hline$t_{b}$ & Resistor Burn-Off Time \\
\hline$\Delta t_{b}$ & Difference between Resistor Burn-Off Times \\
\hline$\Delta t$ & Total Burn Time \\
\hline UCF & The University of Central Florida \\
\hline
\end{tabular}




\section{TABLE OF CONTENTS}

Page

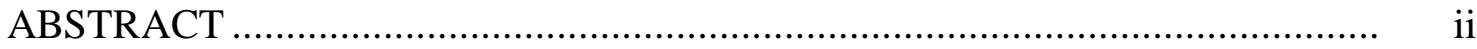

ACKNOWLEDGEMENTS ................................................................... iii

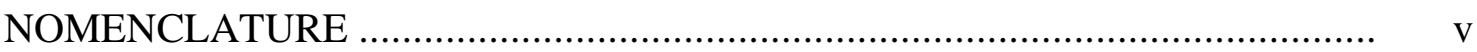

TABLE OF CONTENTS .......................................................................... viii

LIST OF FIGURES ....................................................................... ix

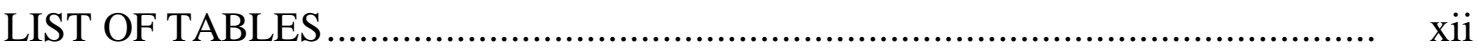

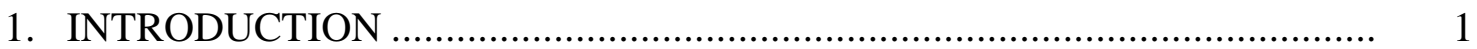

2. REGRESSION RATE MEASUREMENT TECHNIQUES …....................... 5

3. ENERGETIC ADDITIVE CHARACTERIZATION .................................... 10

4. DEVELOPMENT OF MOTOR MANUFACTURING PROCEDURES........... 14

4.1 Plain HTPB Motors and Motors Containing Commercial Aluminum . 14

4.2 Motors Containing Novel Aluminum ......................................... 26

5. MOTOR TESTING PROCEDURES..................................................... 32

6. RESULTS AND DISCUSSION ........................................................... 35

7. CONCLUSIONS AND FUTURE WORK............................................... 46

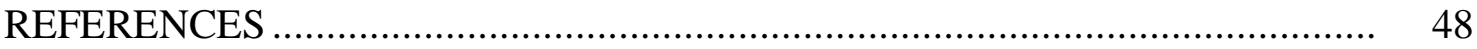




\section{LIST OF FIGURES}

FIGURE

Page

1 Illustration showing enhanced radiation heat fluxes from the diffusion flame to the regressing fuel surface due to the presence of aluminum particulate additives

2 Representative MIRRAS sensor used to measure the burning rate in experimental hybrid motors. There are 40 resistive rungs spaced 0.0125 inches apart yielding a high regression rate resolution.

3 TEM images of cross-sections of cured HTPB composite containing 5\% commercial aluminum nano-particles produced by the EEW method......

4 SEM images of sample cross-sections of (a) a plain HTPB hybrid motor with no additives and (b) a hybrid motor containing 5\% commercial aluminum nano-particles produced by the EEW method.

5 First prototype hybrid motor curing test (a) before and (b) after curing ....

6 Second prototype hybrid motor curing test (a) before and (b) after curing....

7 Third prototype hybrid motor curing test (a) before and (b) after curing...

8 Commercially aluminized hybrid motor prototype after curing ....

9 Representative plain HTPB (left) and aluminized (right) experimental motors with a length and diameter of 6 and 3.375 inches, respectively, and a combustion port diameter of 1 inch. MIRRAS sensors are embedded 2 inches from either end and are mounted perpendicular and tangent to the combustion port surface.

10 Burning rate behavior for plain HTPB and aluminized 6-inch long hybrid motors with a 1-inch diameter combustion port compared to literature correlations

11 Average oxidizer mass fluxes versus testing time for plain HTPB and aluminized hybrid motors with various combustion port diameters according to literature correlations. 
12 First novel aluminized prototype hybrid motor curing test ....................

13 Second novel aluminized prototype hybrid motor curing test ................. 28

14 Parametric study of additive effects on bubble formation in novel aluminized HTPB mixtures containing (a) no additive, (b) a low curative level, (c) MDI curative, (d) a high curative level, (e) ACAC, (f) DOA, and (g) silicone oil

15 Schematic representation of the hybrid motor testing apparatus depicting the oxygen feed system, purge system, mounted hybrid motor section, and sensing instrumentation. Pneumatic oxygen valves and an orifice flow plate enable precise control of oxidizer mass flow rate. Various instrumentation including pressure transducers, thermocouples, and MIRRAS sensors allow for measurement of key system parameters during testing.

16 Diagram of a mounted experimental motor showing key dimensions of the testing apparatus including the pre- and post-combustion chambers and nozzle section. The combustion port diameter was modified to $2.54 \mathrm{~cm}$ for testing at low oxidizer mass fluxes. Ignition can be achieved with hypergolic propellant or with a ceramic igniter. Pressure transducer ports are located in both the pre- and post-combustion chamber and MIRRAS sensors are embedded in the hybrid motor.

17 Raw voltage versus time data obtained from two MIRRAS sensors embedded in a plain HTPB hybrid solid grain burning in gaseous oxygen at an average oxidizer mass flux of $1.65 \mathrm{~g} / \mathrm{cm}^{2}-\mathrm{s}$

18 Instantaneous regression rate versus time data calculated from manual data point selection for two MIRRAS sensors embedded in a plain HTPB hybrid solid grain burning in gaseous oxygen at an average oxidizer mass flux of $1.65 \mathrm{~g} / \mathrm{cm}^{2}-\mathrm{s}$

19 Average regression rates for several burns of plain and aluminized HTPB hybrid motors in gaseous oxygen, as a function of oxidizer mass flux. Regression rates are calculated from traditional TOT methods and with regression sensors by implementing linear approximation and manual burn-off point selection techniques

20 Literature correlations of regression rate and experimental TOT method regression rates of plain and aluminized hybrid HTPB motors burning in gaseous oxygen on a standard plot. 
21 Literature correlations of regression rate versus oxidizer mass flux and experimental TOT method regression rates of plain and aluminized hybrid HTPB motors burning in gaseous oxygen on a log-log plot ..........

22 Literature correlations of mass-loss rate versus oxidizer mass flux and experimental mass-loss rates of plain and aluminized hybrid HTPB

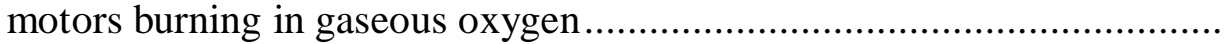




\section{LIST OF TABLES}

TABLE Page

1 Average regression rates, mass-loss rates, oxidizer mass fluxes, and fuel to oxidizer ratios for several burns of plain and aluminized HTPB hybrid motors in gaseous oxygen. Regression rates were calculated from traditional TOT methods and with regression sensors by implementing linear approximation and manual burn-off point selection techniques.

2 Empirical constants for traditional power law regression rate correlations of plain and aluminized hybrid HTPB motors burning in gaseous oxygen. Constants produce regression rate in $\mathrm{mm} / \mathrm{s}$...................

3 Empirical constants for traditional power law mass-loss rate correlations of plain and aluminized hybrid HTPB motors burning in gaseous oxygen. Constants produce mass-loss rate in $\mathrm{kg} / \mathrm{s}$..................... 


\section{INTRODUCTION}

Rocket propulsion concepts with fuel and oxidizer components stored in different phases are termed hybrid rockets. Traditional hybrid rockets are composed of solid fuel grains and a fluidic oxidizer. These types of hybrid rockets have distinct advantages over their pure solid or liquid counterparts. In particular, they are safer to fabricate, store, and transport; are more controllable due to start and stop capabilities; have smooth thrust transition capabilities; and allow for higher specific impulse and density specific impulse than certain solid propellants and liquid bipropellants, respectively. ${ }^{1}$ Hybrids are also mechanically simpler and allow for denser fuels than liquid propellant systems. The disadvantages of hybrid rockets include a variation in mixture ratio during operation, unavoidable fuel residues, proneness to chugging or pressure instabilities, and comparatively complicated internal motor ballistics. ${ }^{1}$ Additionally, a major drawback of hybrid chemical propulsion is low solid fuel regression rates during combustion that ultimately lead to low engine thrust.

Several methods and techniques have been proposed and explored to overcome the inherently low regression rates associated with hybrid rocket motors. The use of nonpolymeric fuels that allow the oxidizer flow to strip and entrain fuel droplets, such as paraffin, was first suggested by Karabeyoglu et al. ${ }^{2,3}$ These fuels have displayed superior regression rates in comparison to their polymeric counterparts in many studies, ${ }^{2-7}$ but their poor mechanical properties make them incompatible with large-scale motors. ${ }^{7}$ Modification of grain-port geometry by the addition of more ports, reduction in port 
diameter, or reduction in port length have been shown to increase the regression rate. ${ }^{8-12}$ Inducing swirl or vortex flow in the oxidizer stream also leads to enhanced surface regression rates. ${ }^{11-13}$ The inclusion of solid oxidizer in the hybrid motor grain, termed mixed hybrid configuration, increases the burning rate, ${ }^{1,8,9,14}$ but removes the added benefit of enhanced safety associated with traditional hybrids. Numerous particulate additives have been shown to effectively increase hybrid burning rates including bondbreaking catalysts, ${ }^{15}$ metals, ${ }^{5,6,8,9,14,16-19}$ metal hydrides, ${ }^{18}$ and other energetic additives.

Aluminum particles, both on a micro- and nano-scale, are probably the most well-studied particulate inclusion in hybrid motors owing to their capability to increase regression rates and serve as a secondary fuel source. Micro-scale aluminum increases solid grain regression rates through enhanced radiation heat fluxes from the diffusion flame zone back to the fuel surface. ${ }^{6}$ Nano-scale aluminum has the same effect, but also has much lower ignition temperatures, due to a high specific surface area, resulting in energy release closer to the fuel surface. ${ }^{6}$ This enhanced regression rate phenomenon is illustrated in Figure 1. Traditional nano-scale aluminum additives have several shortcomings including a reduction in active aluminum content due to the presence of an oxide shell and a tendency to agglomerate, reducing the additive's specific surface area and dispersion uniformity. Variation in mixing techniques can have profound consequences on the dispersion of the additive. To minimize or eliminate the oxide layer, the aluminum particles can be passivated or coated with an alternate chemical such as a polymer, epoxide, acid, metal, etc. 


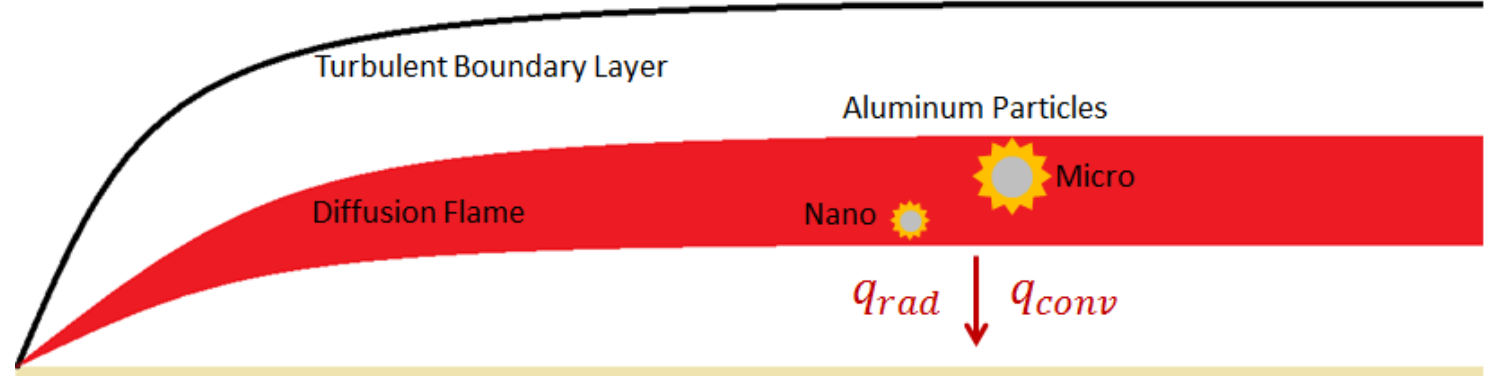

Solid HTPB Fuel

Figure 1. Illustration showing enhanced radiation heat fluxes from the diffusion flame to the regressing fuel surface due to the presence of aluminum particulate additives.

Energetic nano-scale Aluminum has proven to be an effective catalyst in composite solid propellants containing hydroxyl-terminated-polybutadiene (HTPB $)^{20-24}$ and in hybrid propellants with a solid HTPB grain. ${ }^{5,6,16,18}$ To support this hypothesis, the author was motivated to manufacture and test several hybrid motors, including some with commercial nano-Aluminum additives. Additionally, a novel aluminum additive developed by the author's laboratory in conjunction with partners at the University of Central Florida (UCF) will be included in future motors. The experiments described herein were performed to develop the requisite techniques in the author's laboratory, to confirm burning rate enhancement in HTPB hybrid motors by the addition of nano-scale aluminum, and to establish baseline burning rate values for future hybrid motor testing.

The remainder of this thesis provides background information, experimental procedures, and results regarding the evaluation of commercial and novel nanoaluminum inclusion in hybrid motors with solid HTPB fuel grains burned in gaseous oxygen. The regression rate measurement techniques chapter includes background 
information on methods used to measure solid fuel regression rates in hybrid motors and details the two techniques implemented in this study. Experimental procedures and relevant results of imaging techniques, applied to better understand the inclusion of commercial and novel aluminum particles in hybrid fuel grains, are presented in the energetic additive characterization chapter. The development and improvement of motor fabrication techniques, as well as problems encountered and solutions employed during this improvement process, are presented in the development of motor manufacturing procedures chapter. The motor testing procedures chapter includes experimental details on the lab-scale burner apparatus and procedures for burning hybrid motors. Experimental results are summarized with a brief discussion in the results and discussion chapter. Important conclusions and areas of future work are given in the final chapter of this thesis. 


\section{REGRESSION RATE MEASUREMENT TECHNIQUES}

The solid fuel phase of a hybrid motor contains no oxidizer, so combustion processes take place after the fuel and oxidizer are mixed during the reacting flow process. The fuel must vaporize before burning, and the fuel surface regression rate is intrinsically related to fluid dynamics and heat transfer within the combustion port. ${ }^{1}$ Factors affecting the fuel regression rate include operating pressure ${ }^{1,8,12,25}$ and temperature, ${ }^{1}$ fuel/oxidizer composition, oxidizer mass flow rate, ${ }^{1,25-28}$ combustion port geometry, ${ }^{1,8,12}$ and axial port location. ${ }^{1,29}$ At very low and high oxidizer mass fluxes, thermal radiation and gas-phase chemical kinetics mechanisms, respectively, dominate fuel regression behavior in hybrid motors. ${ }^{1,29}$ Strand et al. ${ }^{19}$ showed that at normal motor operating conditions, turbulent boundary layer heat transfer is the limiting process for combustion and decomposition of solid hybrid grains. Lewin et al. ${ }^{12}$ demonstrated that the regression rate in these operating ranges is approximately pressure independent. For preliminary design or experimentation purposes, aerodynamic, thermochemical, and fluidic effects are lumped together in a single parameter. ${ }^{1}$ The resulting equation for regression rate, $r$, of a solid hybrid fuel grain is given by the traditional power law:

$$
r=a G_{o x}^{n}
$$

where $a$ and $n$ are empirically fitted constants, and $G_{o x}$ is the oxidizer mass flux.

Many methods have been developed to measure the fuel regression rate of hybrid motors and to determine the corresponding empirical power law constants. Spatially and temporally averaging procedures based on thickness over time (TOT) measurement 
techniques are employed because of their simplicity and ease of implementation. ${ }^{5,8,13,30,31}$ These measurements are usually applied to lab-scale motors, but De Luca et al. ${ }^{32}$ have recently applied the method to an even smaller motor termed a microburner. Other methods of measurement include time-resolved optical measurements, ${ }^{5,31}$ ultrasound pulse echo systems, ${ }^{31,33}$ real-time X-ray radiography systems, ${ }^{18,31,33}$ measurement of Helmholtz frequencies with pressure transducers, ${ }^{34}$ plasma capacitance gauge systems, ${ }^{31}$ microwave reflection methods, ${ }^{31}$ and resistance-based regression measurement techniques. $^{31}$

In traditional TOT methods, the diameter of the motor's combustion port is measured before and after burning to calculate the average regression rate and oxidizer mass flux. The process is repeated for multiple testing conditions, and the calculated burning rates are plotted against the corresponding oxidizer mass fluxes. The traditional power law, Equation (1), is then fitted to the data to yield the empirical constants for the test motor formulation. The mass flow rate of each motor firing is typically monitored with an orifice mass flow meter. However, the average mass flow rate for a single test, oxidizer mass flow rate, or $\dot{m}_{o x}$, can be calculated with the ideal gas law from initial and final testing conditions:

$$
\dot{m}_{o x}=\frac{\Delta m_{o x}}{\Delta t}=\frac{M V}{\bar{R} T}\left[\frac{\left(P_{i}-P_{f}\right)}{(\Delta t)}\right]
$$

where $\Delta m_{o x}$ denotes the change in mass of oxidizer in the tank, $\Delta t$ denotes the total burn time, $M$ is the molecular weight of the oxidizer, $V$ is the volume of the oxidizer tank, $\bar{R}$ is the universal gas constant, $T$ is the temperature of the oxidizer in the tank, and $P_{i}$ and 
$P_{f}$ are the initial and final tank pressures, respectively. The average cross-sectional area of the motor during the burn is defined by:

$$
\overline{A_{c}}=\frac{\pi}{4} \bar{D}^{2}=\frac{\pi}{16}\left(D_{i}+D_{f}\right)^{2}
$$

where $\bar{D}$ is the average port diameter, and $D_{i}$ and $D_{f}$ are the initial and final port diameters, respectively. The average oxidizer mass flux for a single motor test, $\bar{G}_{o x}$, can be calculated from the oxidizer mass flow rate and the average port cross-sectional area, as shown below:

$$
\bar{G}_{o x}=\frac{\dot{m}_{o x}}{\bar{A}_{c}}=\frac{16 \dot{m}_{o x}}{\pi\left(D_{f}+D_{i}\right)^{2}}=\frac{16 M V}{\pi \bar{R} T}\left[\frac{\left(P_{i}-P_{f}\right)}{\left(D_{i}+D_{f}\right)^{2} \Delta t}\right]
$$

In addition to surface regression rates, mass burning rates of hybrid motors, $\dot{m}$, can be correlated with the average oxidizer mass flux using a conventional power law:

$$
\dot{m}=b G_{o x}{ }^{m}
$$

where $b$ and $m$ are empirically fitted constants. The mass burning rate can be readily calculated by measuring the mass of the test motor before and after motor firing. The mass-loss rate is given by:

$$
\dot{m}=\frac{\Delta m}{\Delta t}=\frac{m_{i}-m_{f}}{\Delta t}
$$

where $\Delta m$ is the change in motor mass during the burn or the amount of solid grain burned, and $m_{i}$ and $m_{f}$ are the initial and final motor masses, respectively.

Resistance-based regression sensors are embedded in test motors and burn away with the motor. The use of resistors to measure the continuous burning rate of hybrid propellants was first proposed by Stromberg et al. ${ }^{35}$ in 1968. Several research groups, including Monti et al. ${ }^{36}$, explored various theoretical geometries for such sensors and 
developed working systems. In conjunction with NASA, Orbital Technologies Corporation designed a working resistive regression sensor system, termed miniature resistive regression and ablation sensor (MIRRAS), at the beginning of the millennium. A MIRRAS sensor, like the one employed in the present study, is shown in Figure 2. These sensors consist of a conductive leg structure, a resistive material, a substrate binder, and a lead connector. The resistive material can be a continuous strip or discretized along the substrate like the sensor in Figure 2. The principle of the measurement method is that the sensor burns away with the regressing motor, and the resistance of the sensor is related to its instantaneous length. ${ }^{31}$ The time derivative of these data can yield instantaneous or time-averaged regression rates. Embedded resistance-based regression sensor technologies have unique advantages including small size, low mass, and the potential to transmit real-time regression data which gives rise to potential use on onboard flight systems. $^{37}$ Reliable and accurate resistive-based regression sensors must regress at the same rate as the host material, not adversely affect material regression or the combustion process, and exhibit a resistance that can be precisely correlated to the instantaneous sensor length. ${ }^{31}$ 


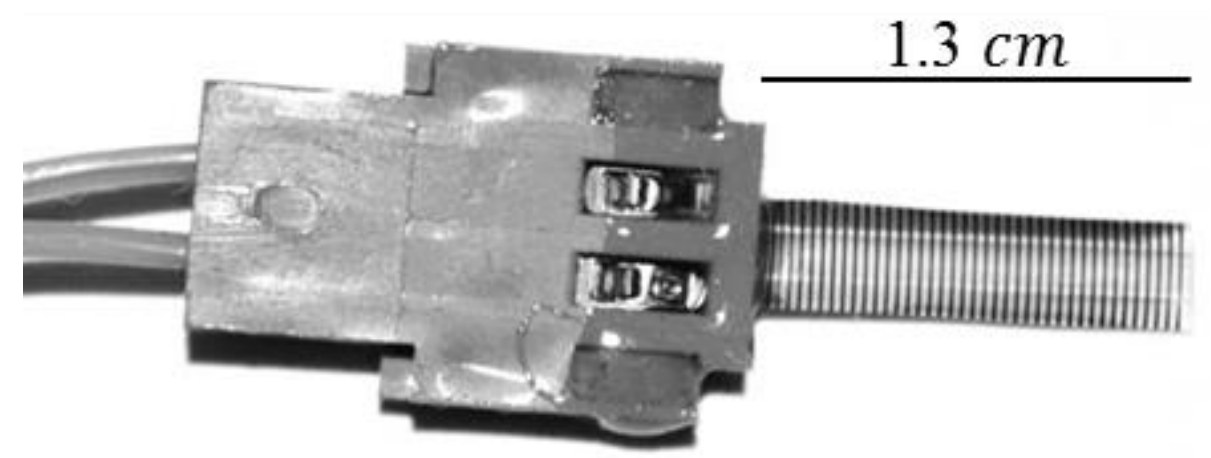

Figure 2. Representative MIRRAS sensor used to measure the burning rate in experimental hybrid motors. There are 40 resistive rungs spaced 0.0125 inches apart yielding a high regression rate resolution.

The current study employed MIRRAS sensors with a resolution of 0.0125 inches to measure the regression rate of plain and aluminized hybrid motors burning in gaseous oxygen. Instantaneous and time-averaged regression rates are calculated from MIRRAS data using various methods including linear fit approximations, manual data point selection, and Fast Fourier Transforms (FFT). Regression rates calculated from MIRRAS data are compared to burning rates calculated with traditional TOT methods in the results and discussion chapter of this thesis. 


\section{ENERGETIC ADDITIVE CHARACTERIZATION}

The combustion properties and behavior of additive particles, and the composite in which they are included, are inherently tied to their size, composition, structure, surface characteristics, method of inclusion, and many other factors. Accordingly, it is necessary to characterize additives to adequately understand how they will affect the composite motors in which they are included. This chapter summarizes several experimental techniques applied to better understand the properties of the commercial and novel aluminum particles.

Nano-aluminum, produced by the electrical explosion of wire (EEW) method, was commercially purchased from US Research Nanomaterials, Inc. and included in loaded motor formulations. The commercial aluminum has a prescribed diameter of 100 $\mathrm{nm}$ and specific surface area of $10-20 \mathrm{~m}^{2} / \mathrm{g}$. Several imaging techniques were employed in order to characterize the commercial additive aluminum. Transmission Electron Microscopy (TEM) images were taken on a FEI Tecnai G2-F20 TEM to confirm the aluminum particle size and characterize its dispersion. TEM samples were prepared by dispersing nano-aluminum particles in a HTPB solution at a mass concentration of 5\% and subjecting the mixture to a 15-minute ultra-sonication treatment to enhance particulate dispersion. The mixture was cured with isophorone diisocyanate (IPDI) and placed on a cryogenic grid for imaging. Figure 3 shows TEM images of cured HTPB containing 5\% EEW aluminum at various magnifications. The nano-particles agglomerated into clusters ranging between $0.5-1 \mu \mathrm{m}$ in size and exhibit an interparticle 
spacing greater than $1 \mu \mathrm{m}$ between the agglomerates. Individual aluminum particles are spherical in shape, approximately $100 \mathrm{~nm}$ in size, and are coated with a uniform oxide layer that is approximately $4.5 \mathrm{~nm}$ thick. Most of the mixture volume is void of aluminum particles due to poor particle dispersion.
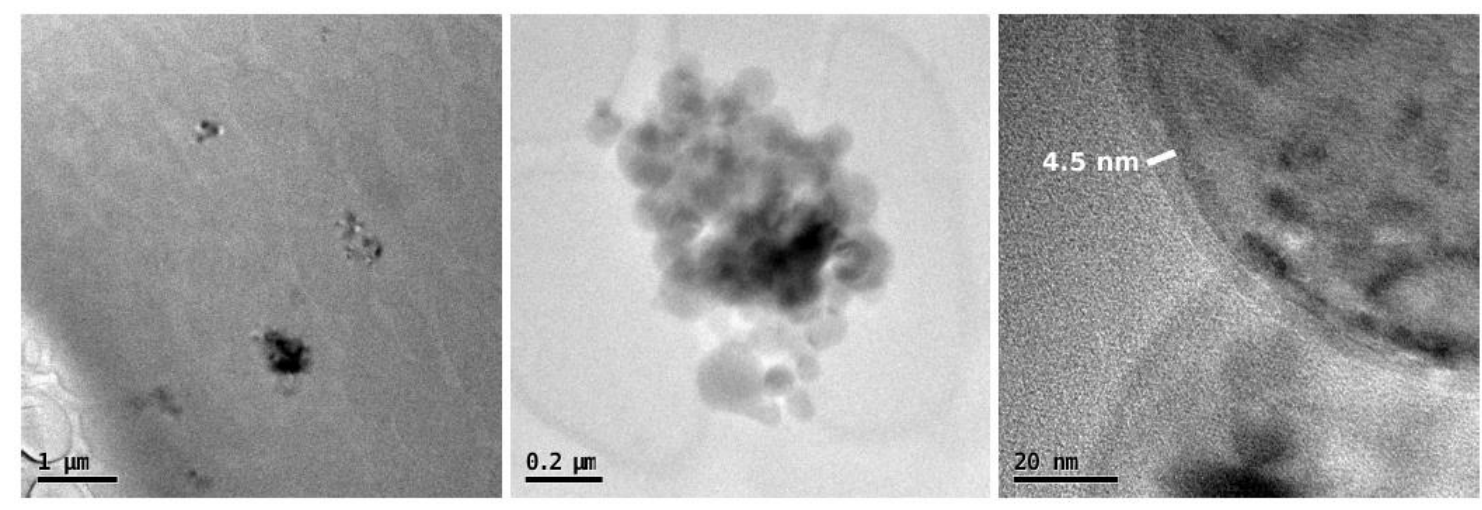

Figure 3. TEM images of cross-sections of cured HTPB composite containing 5\% commercial aluminum nano-particles produced by the EEW method.

To confirm the presence of nano-aluminum in aluminized hybrid formulations, Scanning Electron Microscopy (SEM) images were taken on a JEOL JSM-6400 SEM. SEM samples were prepared by cutting thin slices away from the ends of fabricated motors. These thin slices were placed in an in-house-manufactured guillotine and sliced with a high shear force to retard the material's ductile response and to produce a clean, flat imaging surface. Figures $4 \mathrm{a}$ and $4 \mathrm{~b}$ are SEM images of samples taken from plain HTPB and aluminized hybrid motors, respectively. Figure 4a shows the absence of any inclusions or additives in the plain HTPB motors. In Figure 4b, the presence of relatively well dispersed nano-aluminum particles in the hybrid motor can be seen as white 
contrasted dots. The presence of these aluminum particles was also confirmed with Energy Dispersive X-ray Spectroscopy (EDX) on the same SEM.

a)

\section{b)}

Figure 4. SEM images of sample cross-sections of (a) a plain HTPB hybrid motor with no additives and (b) a hybrid motor containing 5\% commercial aluminum nano-particles produced by the EEW method.

A new method of producing nano-particulate aluminum dispersed in HTPB has been developed through collaboration of Texas A\&M University's (TAMU) Propulsion Laboratory and UCF's Advanced Materials Processing and Analysis Center. An extensive materials characterization project has been completed to better understand the behavior of this novel aluminum during normal handling procedures, motor mixing and fabrication, and during combustion processes. However, the novel aluminum synthesis method is not discussed in this thesis and only a brief materials characterization summary is given below to familiarize the reader with pertinent details.

Several imaging techniques were employed in order to characterize the novel additive aluminum. TEM images were taken according to the previously described 
procedure. Analysis of numerous TEM images confirmed that the nano-particles are homogenously dispersed and are not agglomerated, unlike the commercial additive, so that aluminum particles are present throughout the mixture volume. The nano-particles are roughly $10 \mathrm{~nm}$ in diameter, and have a surface layer that is approximately $3.4 \mathrm{~nm}$ thick. Furthermore, the particles are not uniform in size, so that a particle size distribution exists. An intensive TEM image analysis revealed that the mean particle diameter is between $12-13 \mathrm{~nm}$ and interparticle spacing is on the order of 20-30 nm.

It is worth noting that a unique passivation technique was applied to the nanoparticles to tailor their surface chemistry. Energy-Filtered TEM (EFTEM) analysis was implemented on individual novel aluminum particles to evaluate the surface layer and determine its chemistry and atomic structure. 


\section{DEVELOPMENT OF MOTOR MANUFACTURING PROCEDURES}

Developing procedures to manufacture hybrid motors with and without additives is not a trivial task. Preliminary research and experience with composite solid propellants and liquid monopropellants were used to produce initial fabrication procedures. Many prototype motors were produced to implement solutions to several problems encountered with manufacturing these hybrid fuel grains. Problems encountered, potential solutions, experimental testing, and redesign methods associated with the timeline of this procedural development process are detailed in this chapter of the thesis.

\subsection{Plain HTPB Motors and Motors Containing Commercial Aluminum}

Initial motor dimensions were provided by the Aerospace Corporation according to the specifications of their previously developed testing apparatus, which is presented in the Testing Procedures chapter of this thesis. The test rig was initially set up to accommodate a commercial convolute phenolic motor casing, purchased from Rocket Motor Components, Inc., with an inner diameter of 3.375 inches, an outer diameter of 3.610 inches, and a length of 6 inches. The initial combustion port diameter was provided as 1 inch.

The initial motor curing baseplate was formed by drilling a 1-inch hole in the center of a sheet of 8-gauge steel. The motor casing was secured to the steel plate by means of standard silicone adhesive. A PVC pipe was turned down on a lathe to an outer diameter of 1 inch to serve as the combustion port dowel. The dowel was inserted into 
the center of the plate and sealed to the mold. Preliminary mixing procedures were developed based on the experience of fellow lab researchers with the mixing of smallscale solid propellant strands. All motors were manufactured with HTPB R45-M, obtained from Firefox Enterprises, and cured with isophorone diisocyanate (IPDI), obtained from Sigma Aldrich, at a curing ratio $(-\mathrm{NCO} /-\mathrm{OH})$ of one. This curing ratio has been shown to yield a high binder ductility while retaining a large ultimate strength. ${ }^{37,38}$ Plain HTPB and IPDI were measured out on a high-accuracy scale with a resolution of $0.01 \mathrm{~g}$, mixed by hand in a glass beaker, and poured into the motor mold. The mixture was allowed to cure inside an oven at $63{ }^{\circ} \mathrm{C}$, which accelerates the curing reaction, for one week before being removed. The motor was then cut from the baseplate with a handheld hacksaw. The first prototype motor curing test is shown in Figure 5, before and after curing had taken place. As seen, the cured motor contained a significant amount of macro-scale voids throughout the entire volume of the test motor. Additionally, the combustion dowel was not able to be removed from the motor due to a high strength bond between the cured polymer and the PVC surface. This strong bond was attributed to the roughness of the PVC dowel, as can be seen in Figure 5, due to instabilities in the lathe turning process. 


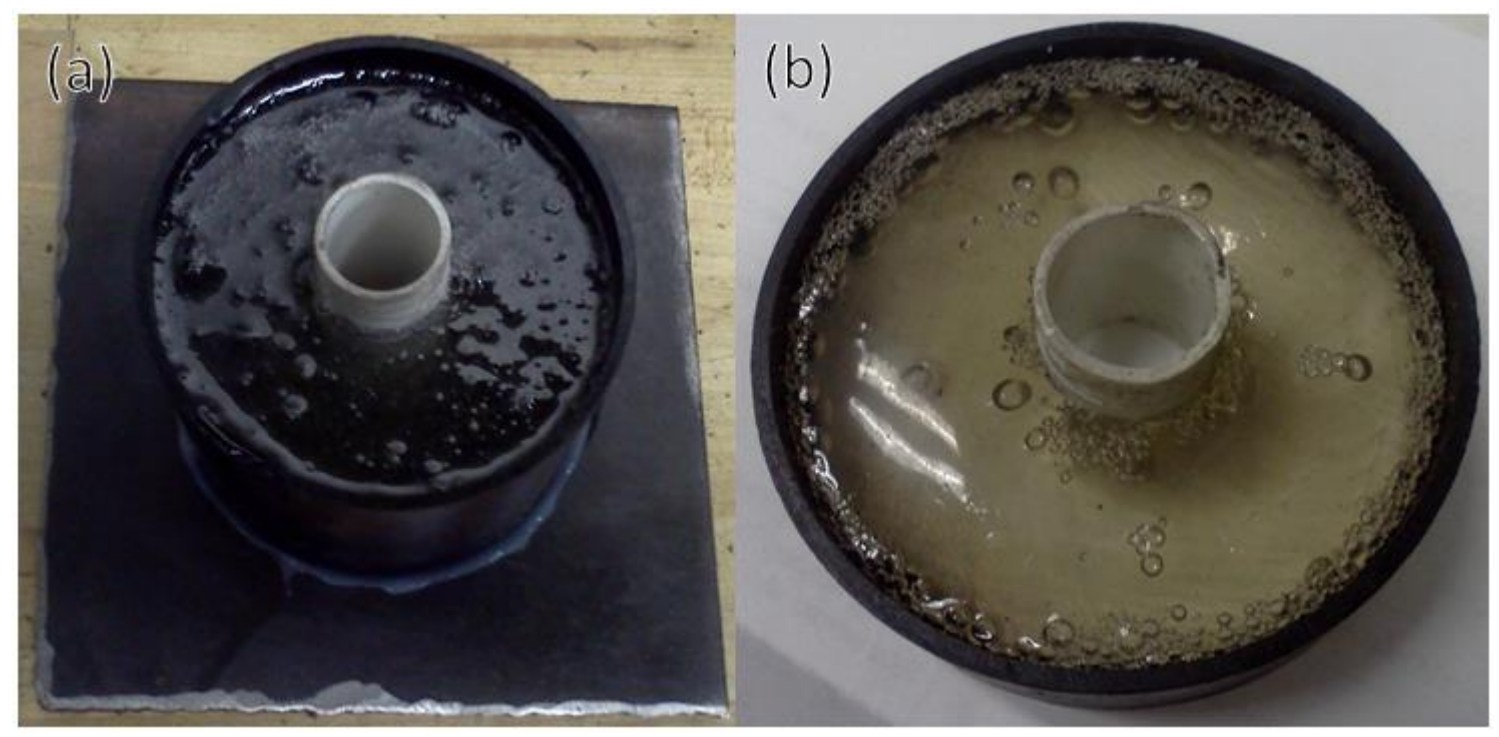

Figure 5. First prototype hybrid motor curing test (a) before and (b) after curing.

Research of hybrid rocket literature revealed that residual voids or bubbles within the solid grain are not an uncommon problem, and many solutions exist. The most robust and widespread solution to this problem was to cure the motor inside of a vacuum chamber. A vacuum pump system already existed in the author's laboratory due to the group's work with solid propellants, so a vacuum chamber was purchased from Thermo Scientific's Nalgene department. The motor baseplate would not fit inside of the vacuum chamber, so it was cut into a circle of approximately 4-inch diameter on a plasma cutting torch. The PVC pipe lathe turning process was modified, by adding a spindle to the unsecured pipe end, to produce a much-smoother combustion port dowel in an attempt to allow for a removable dowel after curing. The second medium-scale motor curing test had mixing procedures almost identical to that of the first one, but the motor was allowed to cure inside of the vacuum chamber for a full day before being moved to the 
curing oven. The second prototype motor curing test is shown in Figure 6, before and after curing had taken place. The cured motor still contained several macro-scale voids near the motor surface and along the casing sides. Additionally, the combustion dowel was still not able to be removed from the motor. It should be noted that in Figure 6a there is a foam phase at the top of the motor from pulling out entrained air bubbles. The height of this foam layer limited the strength of vacuum that could be pulled on the motor. To achieve higher accuracy in motor length and provide cleaner-cut surfaces, the prototype motor was cut from its motor casing on a horizontal hydraulic bandsaw.

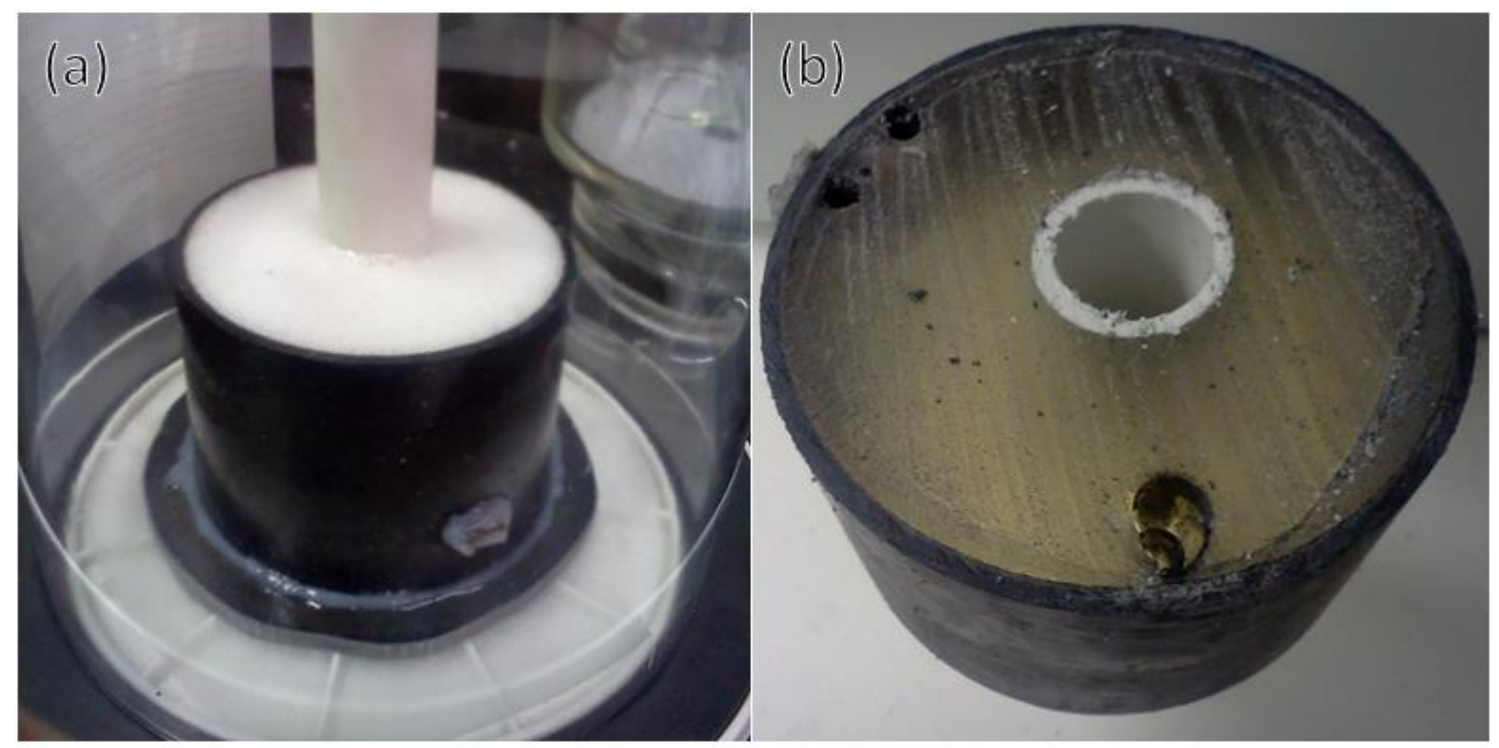

Figure 6. Second prototype hybrid motor curing test (a) before and (b) after curing.

In order to combat the bubble and dowel removal problems, further research was conducted. Previous studies showed that the addition of heat to the mixture before curing or the addition of additives such as silicone oil, surfactant, plasticizer, or acetylacetone 
(ACAC) to the mixture could aid in removal of entrained air bubbles. Additionally, the limitation of vacuum strength previously encountered could be removed by having extra length of the motor casing attached during the curing process or by increasing the time the motor was under vacuum. The same studies suggested that the use of silicone grease, saran wrap, or wax paper around the dowel would allow for easy removal after the motor had cured. Ultimately, a team decision led to the third prototype having saran wrap to aid in dowel removal and a combination of extended motor casing length and vacuum stay time to aid in bubble removal. The third prototype, shown in Figure 7, cured entirely in the vacuum chamber. During the initial curing process, the vacuum level was pulsed from atmosphere to its maximum value, which successfully removed the foam layer. There were no voids present in the cured motor, and the dowel was easily removable.

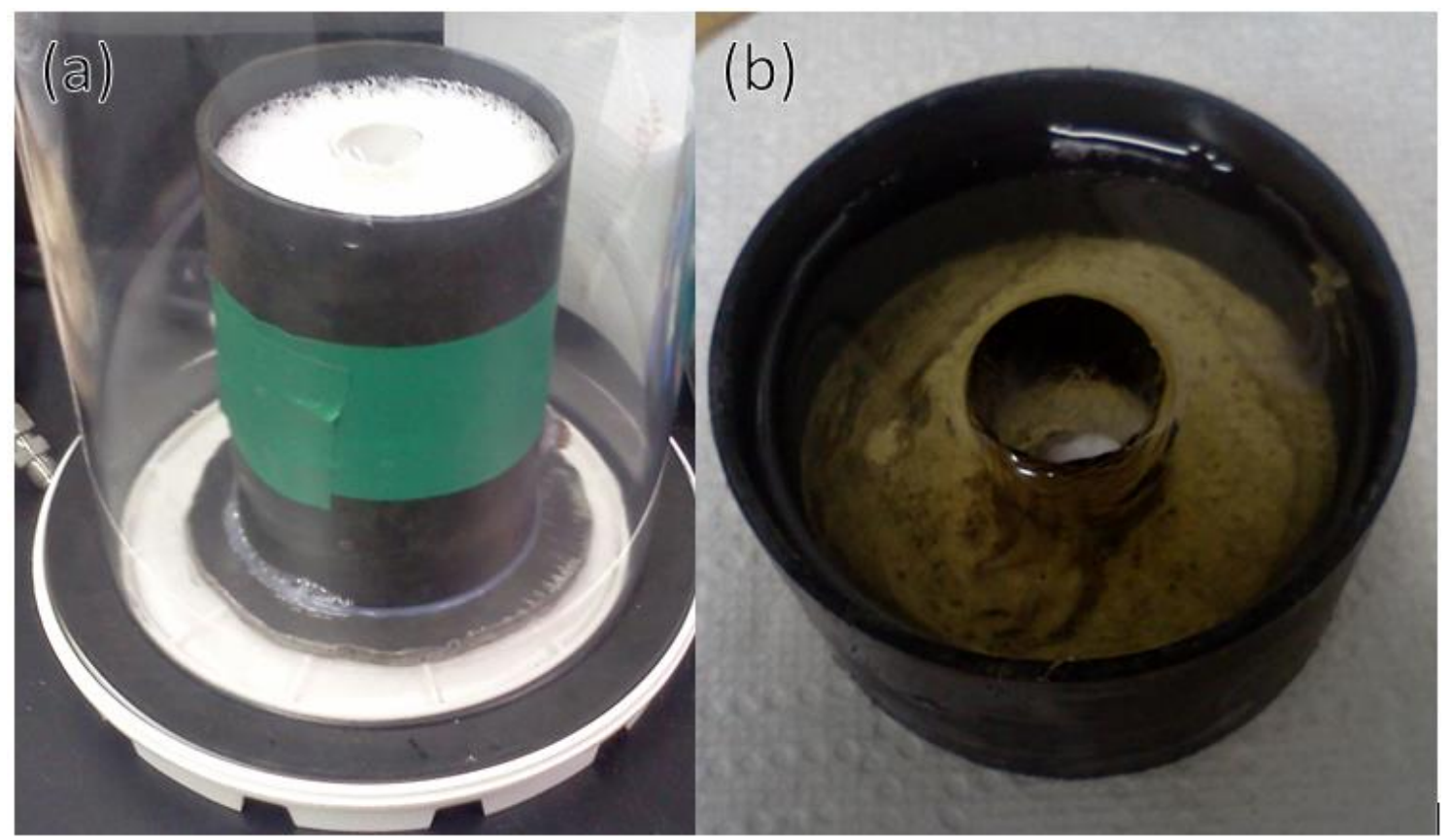

Figure 7. Third prototype hybrid motor curing test (a) before and (b) after curing. 
Initial procedures for the addition of commercial aluminum to the plain HTPB motors were based fellow researchers' experience with nano-aluminum addition in liquid monopropellants. The aluminum nano-powder was hand mixed with HTPB in a glass beaker for 15 minutes to achieve mixture homogeneity. The propellant was then subjected to ultra-sonication at a frequency of $42 \mathrm{kHz}$ for 10 minutes to encourage additive dispersion and to break up potential additive agglomerates. The propellant mixture underwent a vacuum cycle after sonication to remove any remaining entrained air bubbles before the curative was added. The motor was then allowed to cure in the vacuum according to the previously developed procedures. The commercially aluminized prototype, shown in Figure 8, had no voids and appeared to be uniformly dispersed. This uniform dispersion was confirmed through SEM images presented in Figure 4.

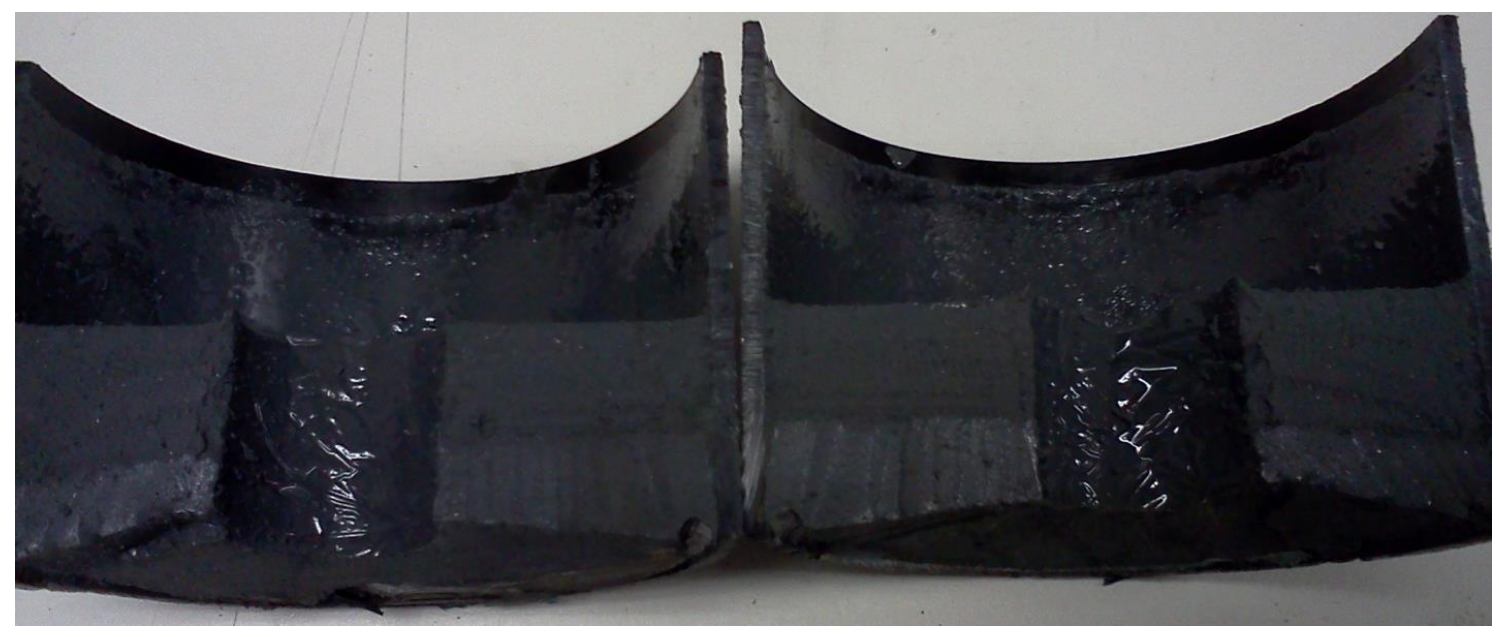

Figure 8. Commercially aluminized hybrid motor prototype after curing. 
Once motor manufacturing procedures had been successfully established for plain HTPB and commercially aluminized motors, full-scale motors could be fabricated. To evaluate the effectiveness, accuracy, and ease of implementation of resistance-based sensors, MIRRAS sensors were embedded in the full-scale motors. At vertical locations of 3 and 5 inches from the bottom of the baseplate, holes were drilled to allow for MIRRAS sensors to be fixed to the hybrid motor. MIRRAS sensors were secured to the motor casing by means of a nut-and-bolt assembly sealed with neoprene washers and silicone. This sensor mount system allowed for accurate alignment of the sensors and permitted the motor casing to hold moderate pressures. The sensors could also be cast into the motor without a mount because the sensor lead wires are rigid enough to allow for stable alignment prior to motor casting. A commercial, high-pressure lead wire feedthrough is suggested when high testing pressures are to be employed in the hybrid motor. The sensors were always aligned so that their leading edge was perpendicular and tangent to the initial burning surface in the combustion port. The fabricated motors had MIRRAS sensors located at the surface of their combustion ports, exactly 2 inches from either end. Figure 9 shows representative plain HTPB (left) and aluminized (right) experimental motors prepared for burning rate testing. The MIRRAS sensor mounting system can also be seen in Figure 9. Multiple plain HTPB motors and motors with 5\% commercial nano-aluminum were manufactured for burning rate testing in a parametric regression rate study. 


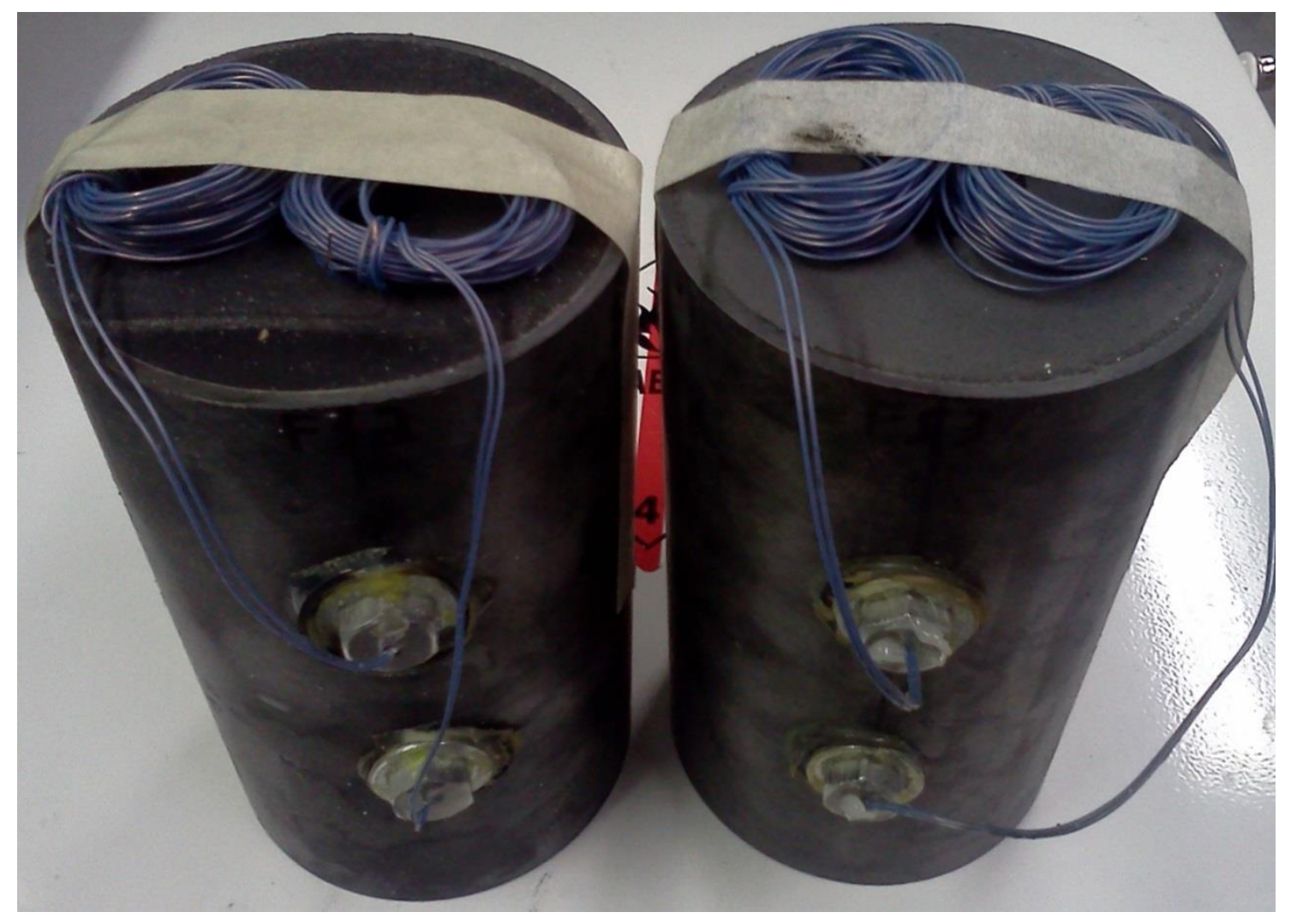

Figure 9. Representative plain HTPB (left) and aluminized (right) experimental motors with a length and diameter of 6 and 3.375 inches, respectively, and a combustion port diameter of 1 inch. MIRRAS sensors are embedded 2 inches from either end and are mounted perpendicular and tangent to the combustion port surface.

Several motors, with the previously given dimensions, were prepared and subsequently sent to the Aerospace Corporation for ballistic evaluation. The pressure tank in the testing apparatus at Aerospace is limited to a maximum pressure of approximately 250 psi which consequently restricts the maximum mass flow rate of the system. A total of six test motors, four plain HTPB and two aluminized, were burned and exhibited a maximum oxidizer flow rate of approximately $18.6 \mathrm{~g} / \mathrm{s}$ which correlates to a maximum mass flux of $2.6 \mathrm{~g} / \mathrm{cm}^{2}$-s with the initial system set up. In order to 
compare the data to literature values and realistic design values, the system mass flux had to be increased to at least $15 \mathrm{~g} / \mathrm{cm}^{2}$-s. This increase in mass flux was accomplished by redesigning the internal combustion port diameter as described below.

The final combustion port diameter for a cylindrical, single-port hybrid motor can be written as

$$
D_{f}=D_{i}+2 \bar{r}_{b} \Delta t
$$

where $\bar{r}_{b}$ is the average fuel regression rate during a motor burning. Equations (7) and (4) can be combined to yield the average oxidizer mass flux as a function of measureable parameters:

$$
\bar{G}_{o x}=\frac{\dot{m}_{o x}}{\bar{A}_{C}}=\frac{4 \dot{m}_{o x}}{\pi\left(D_{i}+\bar{r}_{b} \Delta t\right)^{2}}
$$

If the empirical constants in Equation (1) and the oxidizer mass flow rate are known, then Equations (1) and (8) can be coupled and iteratively solved to yield the average oxidizer flux for a test as a function of testing time and initial combustion port diameter. To determine the empirical constants that most closely matched the motors under consideration, the 6 previously taken data points were plotted against literature correlations for similar motor formulations as shown in Figure 10. The empirical constants from the literature are listed in Table 2 in the Results and Discussion chapter of this thesis. 


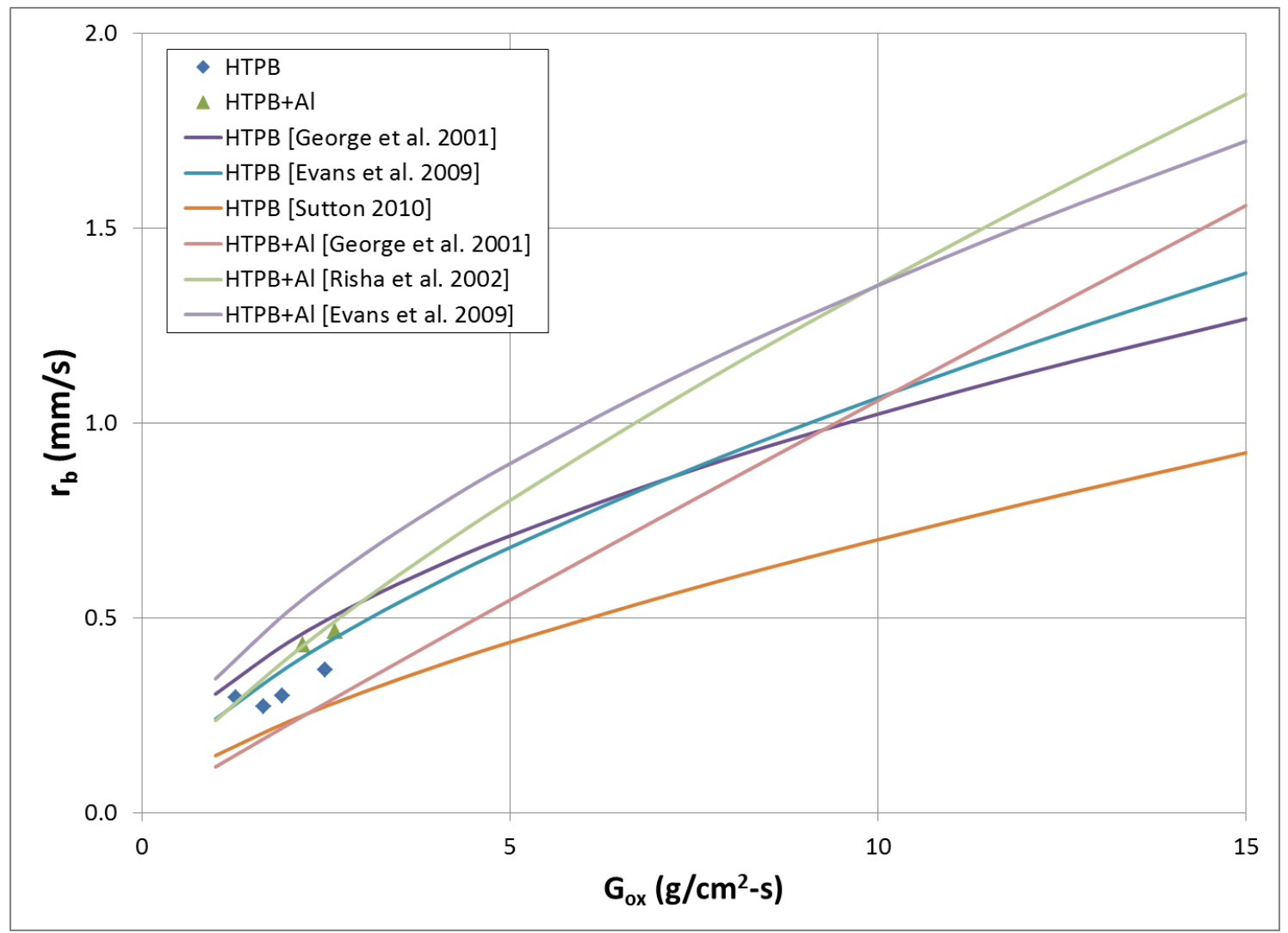

Figure 10. Burning rate behavior for plain HTPB and aluminized 6-inch long hybrid motors with a 1 -inch diameter combustion port compared to literature correlations.

The literature correlations given by Evans et al. ${ }^{16}$ and Risha et al. ${ }^{6}$ best match the burning rate data for plain HTPB and aluminized motors, respectively. Accordingly, the empirical constants given by these authors were used in the iterative solving of Equations (1) and (8). The results of this parametric study are shown in Figure 11 for various initial combustion port diameters. To achieve oxidizer mass fluxes up to 15 $\mathrm{g} / \mathrm{cm}^{2}-\mathrm{s}$, with a minimum testing time of 4 seconds, a new initial port diameter of $5 \mathrm{~mm}$ was selected. 


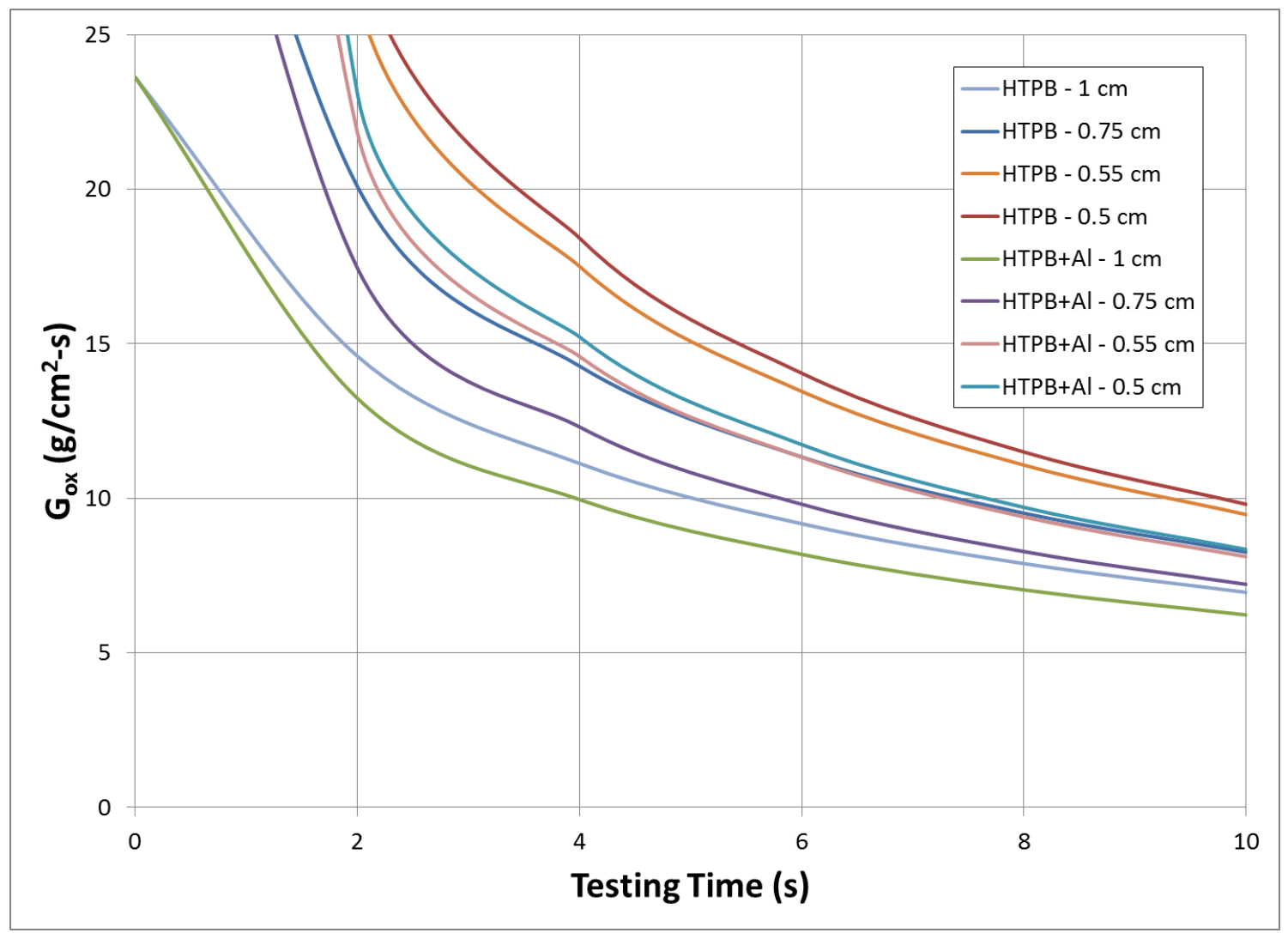

Figure 11. Average oxidizer mass fluxes versus testing time for plain HTPB and aluminized hybrid motors with various combustion port diameters according to literature correlations.

To accommodate the redesigned internal motor diameter, a new motor base plate and mold were manufactured. The baseplate was redesigned to make motor fabrication easier and less work intensive. Motor casting baseplates were manufactured by cutting 10-cm disks from 8-gauge stainless steel and milling a 5-mm deep depressed ring with a diameter of $8.57 \mathrm{~cm}$ (3.375 inches) around the center axis. The center axis was drilled with a $0.5 \mathrm{~cm}$ bit and tapped with UNC 12-24 threads. Square leveling brackets with a width of $8 \mathrm{~cm}$ and height of $5 \mathrm{~mm}$ were welded to the bottom of the casting disk to 
ensure the motor remained level during fabrication and curing. The previously described convolute phenolic motor casings, with an inner diameter of $8.57 \mathrm{~cm}$, were cut to a length of $25 \mathrm{~cm}$ and sealed to the baseplate around the depressed ring with silicone. Combustion port casting dowels were manufactured by adding UNC 12-24 thread to the end of a 5-mm polished, stainless steel rod. The combination of the depressed ring and the screw-in dowel allowed the motor casing to self-align itself and ensured the combustion port of the fabricated motor was at its center axis. A UNC 12-24 jam nut was screwed tightly onto the dowel, under the baseplate, to guarantee the dowel did not move during motor fabrication.

Several full-scale plain HTPB and aluminized motors were fabricated with the new combustion port diameter and shipped to the Aerospace Corporation for burning. The first burning test was prematurely ended due to a rupture in the motor casing. Testing was halted until the cause of failure could be determined. Examination of the testing rig's nozzle dimensions revealed that the throat diameter $(0.87 \mathrm{~cm})$ was larger than the combustion port diameter $(0.55 \mathrm{~cm})$. It was determined that the flow was choked at the head end of the combustion port instead of in the nozzle. To evaluate the effect of this choked flow shift, the rocket chamber pressure was calculated by two methods. In the first method, Fanno flow was assumed in the combustion port. In the second method, the flow was assumed to be choked by the nozzle, and isentropic nozzle flow relations were coupled with thermodynamic equilibrium property calculations. The flow analysis yielded a chamber pressure that was three times larger for the choked port flow case. Accordingly, the combustion port diameter was redesigned to $1 \mathrm{~cm}$ to ensure 
the system was choked at the nozzle throat. This port diameter still allowed for much greater oxidizer mass fluxes than before and would not cause motor failure during testing. The previously described baseplate was simply modified to accommodate the larger dowel rod. Motors that had already been fabricated with the $0.5-\mathrm{cm}$ diameter were drilled through to the new 1-cm diameter.

\subsection{Motors Containing Novel Aluminum}

Developing mixing procedures for motors containing novel aluminum has been much more difficult due to the inherent characteristics of the material. The mixture containing HTPB and 5\% novel aluminum is synthesized at UCF and is shipped to TAMU for testing. The novel aluminum causes the uncured mixture to become thixotropic. This effect is observed as a reversible increase in viscosity, or gelation, that occurs in the absence of active mixing or a lack of shear stress. The origin of this thixotropic effect was thought to be the composite microstructure of the mixture. Due to the homogeneity of the novel aluminum particle dispersion, and lack of agglomeration, the average interparticle spacing is very small and similar to the size of individual HTPB molecules, which causes the HTPB molecules to become entangled with the aluminum nano-particles. This entanglement leads to an increase in viscosity and eventually gelation of the uncured HTPB if continuous mixing is not maintained. The shear force imparted by mixing prevents the entanglement, or reverses the entanglement if gelation has occurred, but the resulting mixture is still much more viscous than pure HTPB. To counteract this effect, a high-shear stand mixer was purchased to return the mixture to its liquid state. Before producing full-scale motors, a prototype motor was cure tested. The 
novel aluminized HTPB mixture was allowed to return to a liquid state in the high-shear mixer, which took approximately 1 hour of agitation. The mixture was warm after agitation due to the high input of mechanical energy into the system. IPDI curative was measured out in a glass beaker and added to the solution. The mixture exhibited an accelerated curing rate untypical of previous mixtures and fully cross-linked within a 5minute period, so it was not able to be cast into a motor mold. The first failed novel aluminized motor prototype is shown in Figure 12.

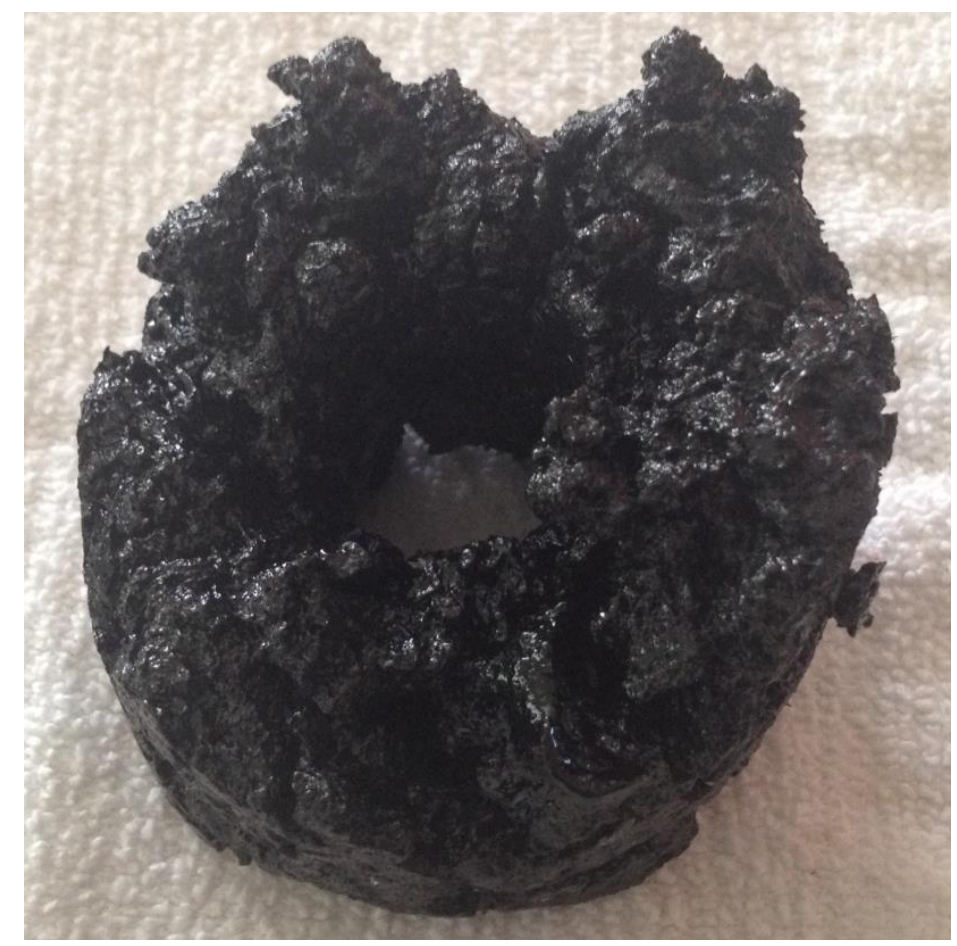

Figure 12. First novel aluminized prototype hybrid motor curing test.

It is well known, as previously mentioned for plain HTPB motors, that increasing the temperature of the curing propellant will accelerate the curing reaction. Additionally, 
it was postulated that a residual chemical complex in the novel aluminum mixture may be catalyzing the crosslinking reaction in the curing propellant. The highly accelerated curing rate of the novel aluminum mixture was attributed to the solution being heated from such a long shear mixing cycle. Accordingly, the second prototype test followed the same procedure as the first, but included an intermittent cooling period, after the agitation cycle, to allow the mixture to return to room temperature. The second prototype curing test is shown in Figure 13.

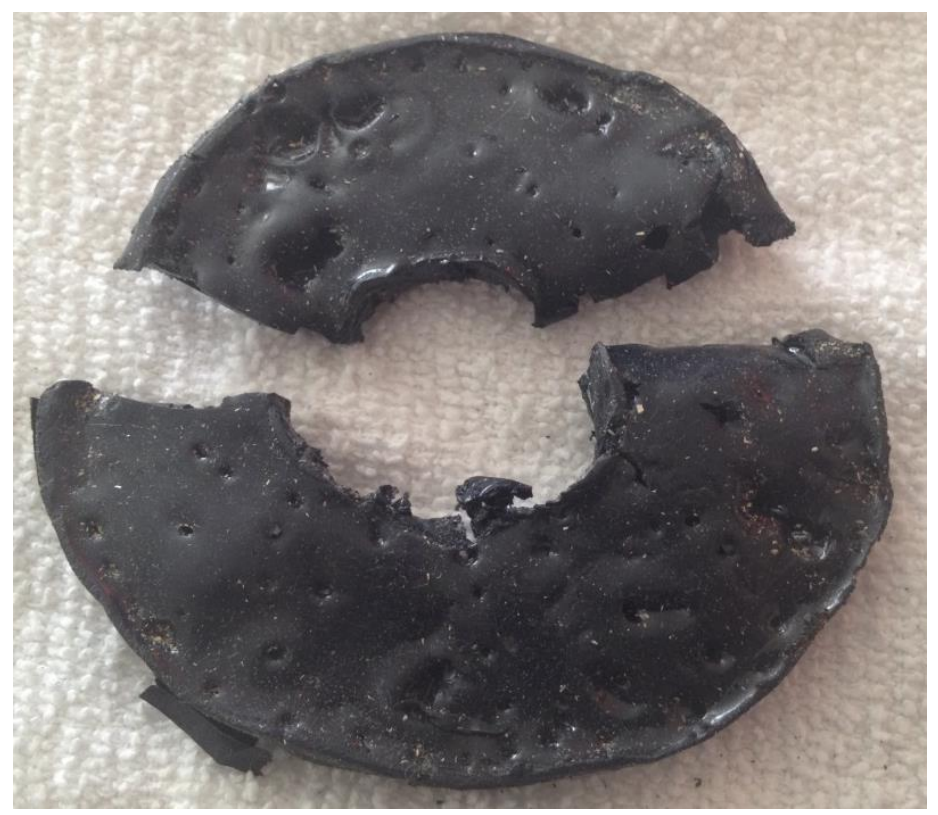

Figure 13. Second novel aluminized prototype hybrid motor curing test.

The cooling period solution was successful in that it slowed the curing reaction down, so that the mixture could be poured into the motor mold. However, the prototype motor still cured faster than motors that didn't contain novel aluminum and was fully 
cured in approximately 2 days. Some residual macro-scale bubbles were left in the propellant after curing took place even though it cured in the vacuum chamber according to procedures that were successful in removing bubbles from plain HTPB and commercially aluminized motor formulations.

It was evident that the higher viscosity of the novel mixture and its accelerated curing rate would not allow for full bubble removal without additional action. To combat this problem, an exhaustive literature search was conducted to find additives capable of aiding in bubble removal or slowing down the curing reaction. The literature search revealed that the use of alternative curing agents or curative ratios, the addition of a plasticizer, the addition of acetylacetone (ACAC), or the addition of a surfactant could significantly affect the cure rate and/or bubble formation and removal.

A parametric study involving all of these solutions, implemented in multiple motor formulations, was conducted. The cured mixtures from this study are shown in Figure 14. The mixture containing surfactant is not shown because it cured too rapidly in an exothermic reaction that did not produce a homogenous propellant. Formulation A was a baseline mixture containing the novel aluminum, HTPB, and IPDI curative at a cure ratio of one. This formulation took approximately 3 days to cure and had multiple residual bubbles, as was observed in past experiments. Formulation B was identical to the baseline, but had a lower cure ratio intended to slow down the crosslinking reaction. This formulation took approximately 4 days to fully cure, but still contained residual bubbles. Formulation D was identical to the baseline, but had a higher cure ratio to test the sensitivity of the baseline to variable cure ratios. This formulation was 
indistinguishable from the baseline in terms of cure time and residual bubbles. Formulation $\mathrm{C}$ was cross-linked with an alternate curative, methylene diphenyl diisocyanate (MDI). An independent literature search by our partners at UCF suggested that this curative in particular was less susceptible to being catalyzed by residual chemicals in the novel aluminum mixture. The formulation containing MDI cured within 5 minutes of being mixed and had the most residual bubbles of all the tested mixtures. Formulation E, which contained ACAC, took approximately 5 days to fully cure, but still contained residual bubbles. Formulation F contained dioctyl adipate (DOA) as a plasticizer. This formulation took approximately a full week to cure, but still retained bubbles in the final propellant. However, these bubbles seemed to only be near the surface of the propellant with the exception of a single large bubble at the bottom of the mixture. Formulation $\mathrm{G}$, which contained silicone oil, took approximately 4 days to cure and contained residual bubbles. A qualitative analysis prior to curing the mixtures indicated that the viscosities of formulations $\mathrm{E}, \mathrm{F}$, and $\mathrm{G}$ were much lower than that of the baseline. Furthermore, formulation F, which contained DOA plasticizer, had the lowest viscosity of all mixtures. 


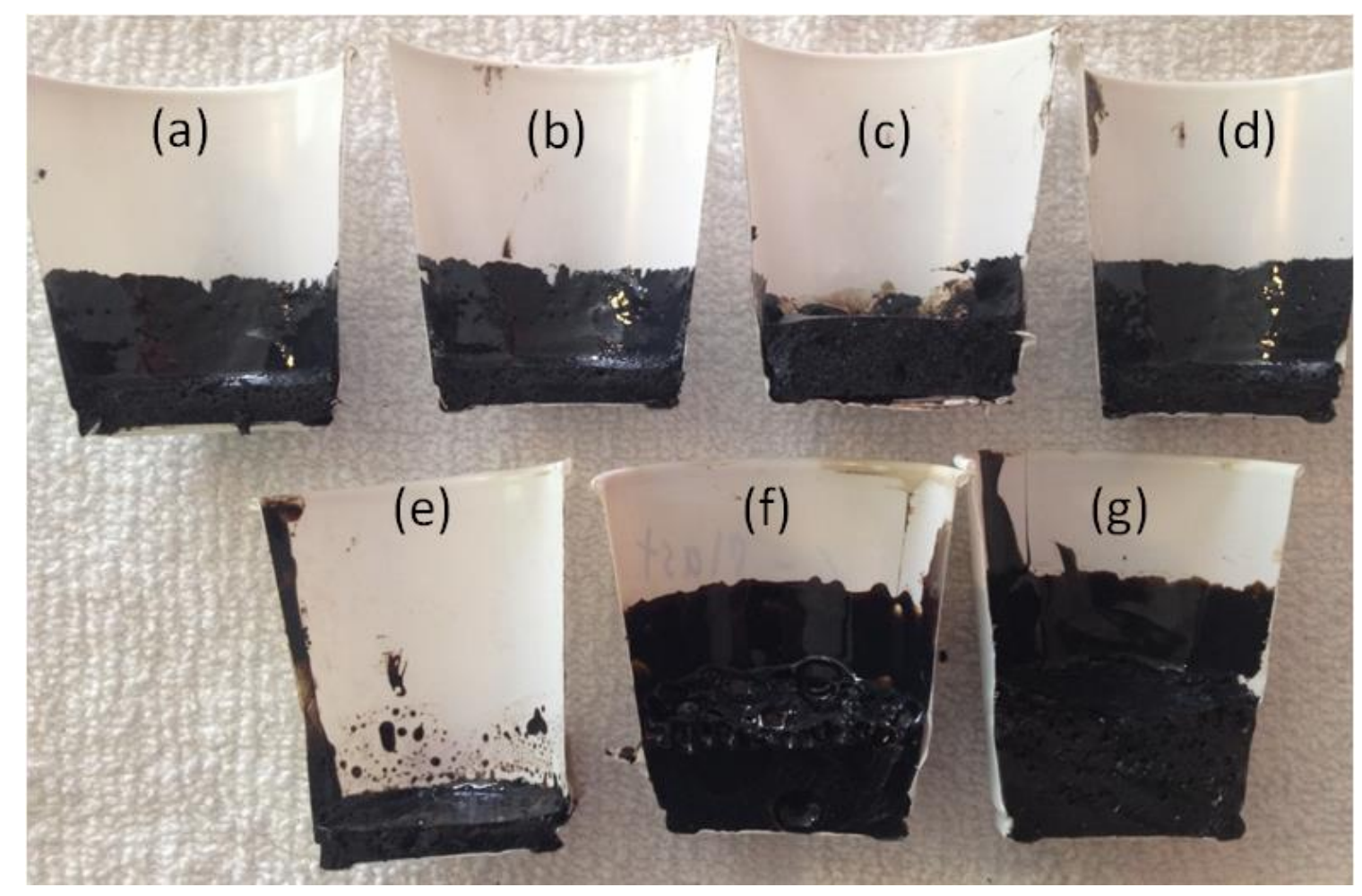

Figure 14. Parametric study of additive effects on bubble formation in novel aluminized HTPB mixtures containing (a) no additive, (b) a low curative level, (c) MDI curative, (d) a high curative level, (e) ACAC, (f) DOA, and (g) silicone oil.

The parametric additive study indicated that no additive is effective enough to both slow the cure rate down and aid in removing all bubbles from the curing propellant. However, DOA plasticizer showed the most promising results in terms of these goals. Currently, our partners at UCF are manipulating their particle production procedures to remove a residual chemical that is thought to catalyze the curing reaction, increase the thixotropic behavior of the material, and increase the mixture viscosity and surface tension. Preliminary testing is promising and has indicated that the procedural change is successful in deterring the problems associated with the novel aluminum mixture, but further testing is necessary to confirm this. 


\section{MOTOR TESTING PROCEDURES}

As mentioned previously, the processed hybrid propellant grains were shipped to The Aerospace Corporation for test firing with gaseous oxygen. Figure 15 depicts a schematic representation of the hybrid-motor burning apparatus. The solid motor grains are mounted into a $7.07-\mathrm{cm}$ diameter combustion chamber attached to a convergingdiverging nozzle with a throat diameter of $0.87 \mathrm{~cm}$. The test motor consists of two stainless steel chambers which serve as the pre- and post-combustion chambers. The precombustion chamber has two oxygen inlets. The first oxygen inlet is a $1.42-\mathrm{cm}$ diameter line that terminates into a $0.63-\mathrm{cm}$ diameter inlet port. The second oxygen inlet is used when the apparatus is started by hypergolic ignition and was not used for the current tests. The second oxygen inlet in the pre-combustion chamber has a smaller diameter of $0.32 \mathrm{~cm}$ and is controlled by an electrically actuated valve. The second stainless steel chamber houses the post-combustion chamber and the exit nozzle. The post-combustion chamber can house a high-speed pressure transducer operating at $1000 \mathrm{~Hz}$. This pressure transducer has been previously used to monitor the Helmholtz frequency during the burn to determine regression rates, similar to other experiments. The post combustion chamber is terminated with a phenolic nozzle with a 9.19-cm outer diameter and a 1.87$\mathrm{cm}$ throat diameter expanding to a $2.28-\mathrm{cm}$ exit diameter. A diagram of the test motor and attached chambers and nozzle is presented in Figure 16. Gaseous oxygen is supplied

to the test motor by a $28,360 \mathrm{~cm}^{3}$ reservoir that can be filled to an initial pressure of up to $1.72 \mathrm{MPa}(250 \mathrm{psi})$. 

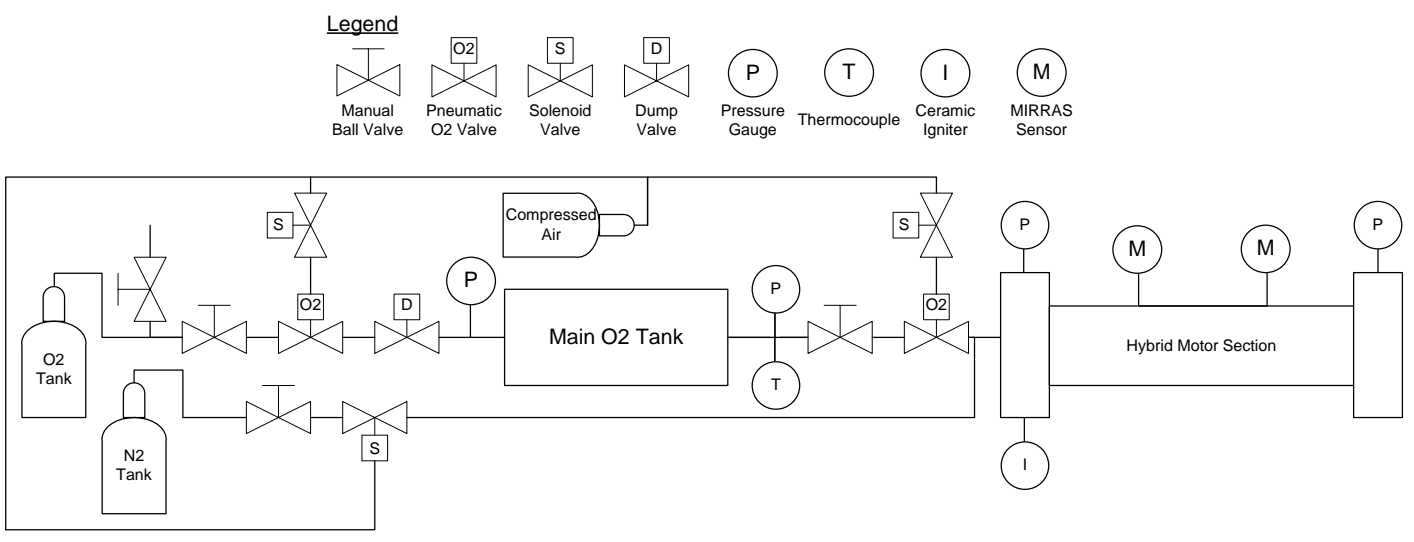

Figure 15. Schematic representation of the hybrid motor testing apparatus depicting the oxygen feed system, purge system, mounted hybrid motor section, and sensing instrumentation. Pneumatic oxygen valves and an orifice flow plate enable precise control of oxidizer mass flow rate. Various instrumentation including pressure transducers, thermocouples, and MIRRAS sensors allow for measurement of key system parameters during testing.

Prior to each hybrid motor test, the initial diameter and mass of the motor were recorded for regression and mass-loss rate calculations. The resistance of each MIRRAS sensor was measured with a voltmeter to check for broken resistors within the sensor. The testing apparatus is located in a shielded enclosure and remotely controlled from a trailer located $10 \mathrm{~m}$ from the cell. When testing, the inlet port was initially filled with paraffin wax to hold back pressurized oxygen in the oxygen reservoir. The line was then exposed to the main oxygen reservoir which had been previously filled from the oxygen tanks that were removed from the test cell. Prior to testing, operators activated a camera to record the test firings and a high-speed data acquisition system (DAQ) to record the pressure and MIRRAS voltage data. The test motor was started by remotely opening the main oxidizer valve and allowing the gaseous oxygen to flow into the pre-combustion chamber. The oxygen was allowed to flow freely through the oxidizer injection port, 
driven by the pressure difference. A squib was remotely ignited and burned in the precombustion chamber to initiate motor firing. Motor firings could be terminated by remotely closing the oxygen inlet valve. After a test was completed, the remaining oxygen supply was vented and the system was purged with inert nitrogen before operators are allowed to reenter the test cell. The final motor diameter and mass were recorded after each firing for ballistic calculations.

Plain HTPB and commercially aluminized hybrid motors have been successfully burned with gaseous oxygen on the previously described testing apparatus. Experimental motors displayed uniform burning based on post-combustion analysis. The results from the experimental HTPB hybrid motors, with and without commercial nano-aluminum particles, are presented in the Results and Discussion chapter of this thesis, as follows.

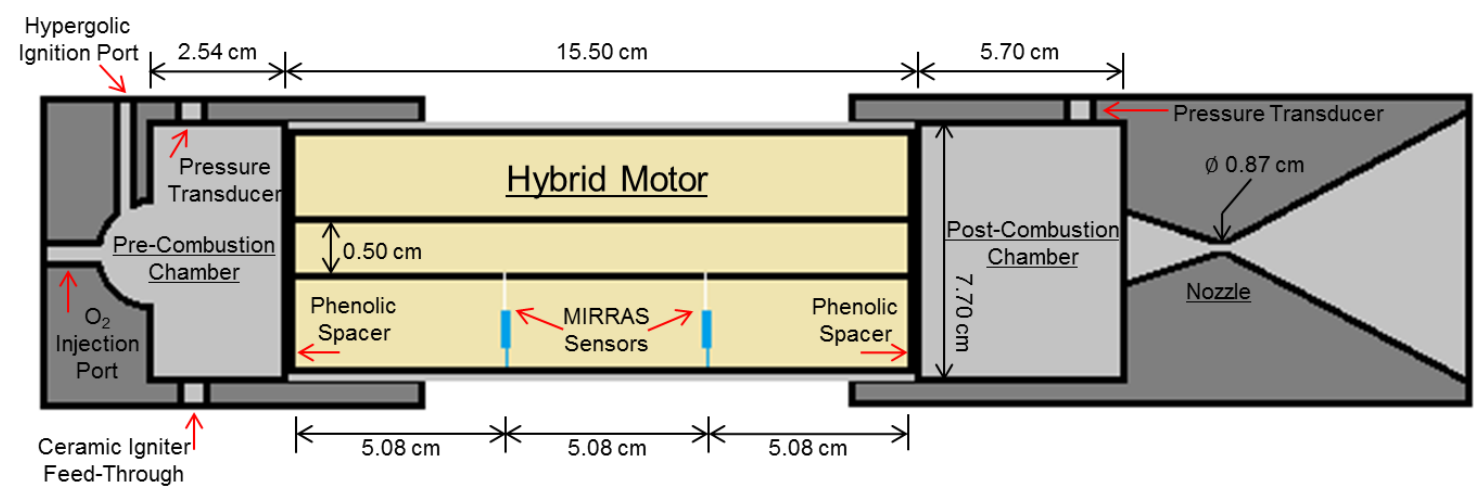

Figure 16. Diagram of a mounted experimental motor showing key dimensions of the testing apparatus including the pre- and post-combustion chambers and nozzle section. The combustion port diameter was modified to $2.54 \mathrm{~cm}$ for testing at low oxidizer mass fluxes. Ignition can be achieved with hypergolic propellant or with a ceramic igniter. Pressure transducer ports are located in both the pre- and post-combustion chamber and MIRRAS sensors are embedded in the hybrid motor. 


\section{RESULTS AND DISCUSSION}

Several plain and aluminized HTPB hybrid motors have been burned with gaseous oxygen and their regression and mass-loss rates have been calculated for various

oxidizer mass fluxes. Motor regression rates were measured using traditional TOT methods and with MIRRAS sensors. Figure 17 shows raw data from two MIRRAS sensors, with a resolution of 0.0125 inches, embedded in a plain HTPB hybrid motor burned with an average oxidizer mass flux of $1.65 \mathrm{~g} / \mathrm{cm}^{2}$-s. Every steep drop in voltage in Figure 17 indicates that an additional resistor rung has burned away or, equivalently, an additional 0.0125 inches of the motor has regressed in the radial direction. The voltage profile increases before dropping off sharply at every resistor burn-off location. This change in voltage is due to an increase in the resistance of the metallic resistor associated with the temperature rise at the regressing motor surface. ${ }^{40}$ The voltage profile in Figure 17 is representative of most MIRRAS data captures, but signal noise was more prevalent in some motor firings. 


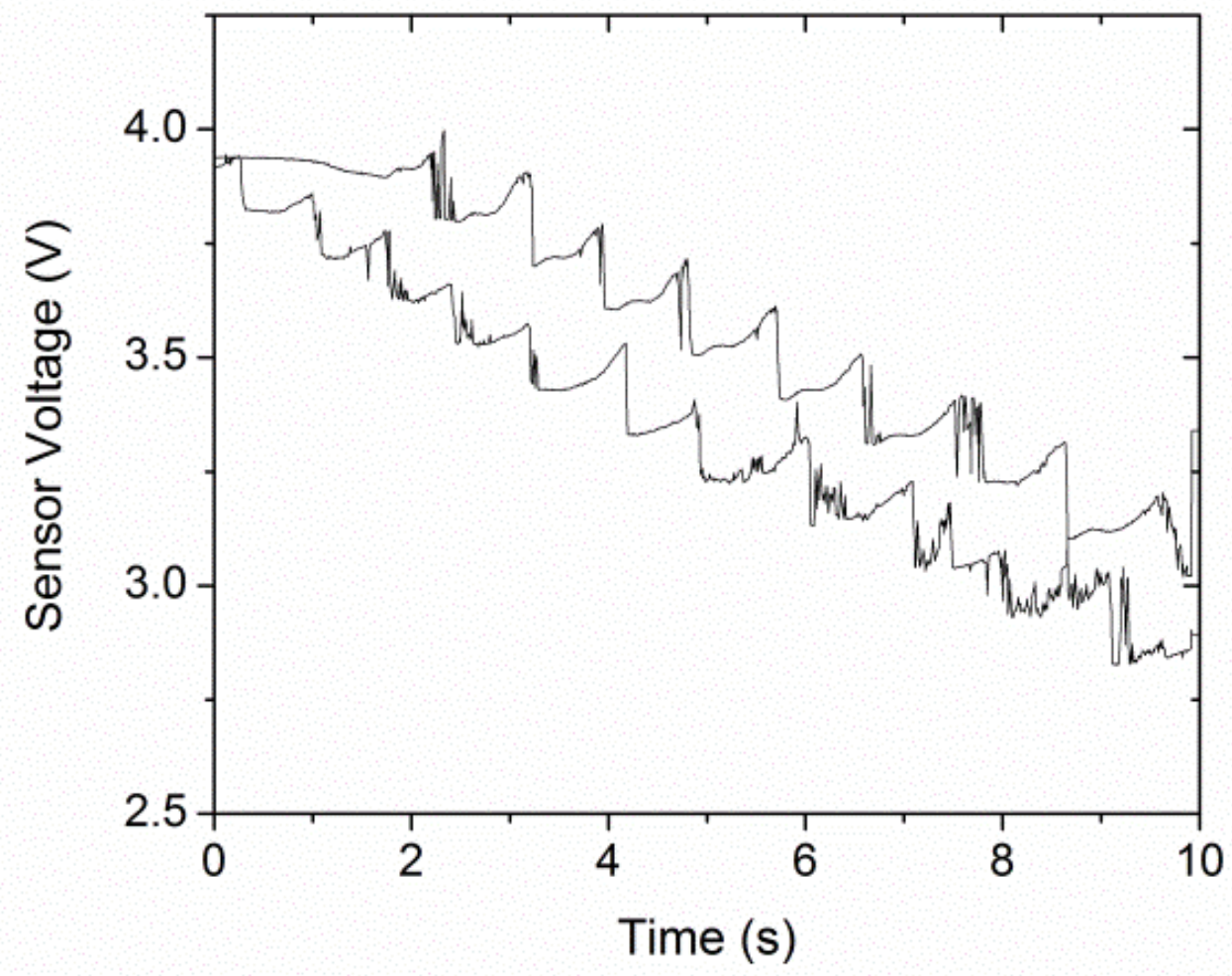

Figure 17. Raw voltage versus time data obtained from two MIRRAS sensors embedded in a plain HTPB hybrid solid grain burning in gaseous oxygen at an average oxidizer mass flux of $1.65 \mathrm{~g} / \mathrm{cm}^{2}-\mathrm{s}$.

Data from the MIRRAS sensors were reduced using several techniques including a best-fit linear approximation relation, manual sensor burn-off point selection, and an FFT method. In the linear method, a linear approximation was fitted to the MIRRAS voltage data. The slope of the best fit linear approximation is proportional to the motor regression rate and the two can be related with the average sensor burn-off voltage drop and the sensor resolution. The linear approximation method is very robust, and the 
regression rate calculated from this method was not significantly affected by signal noise or broken resistors within the MIRRAS sensor.

In the manual method, each resistor burn-off data point was manually selected in the raw data set. These points are located where the voltage profile sharply decreases, as can be seen in Figure 17. The time of each resistor burn-off, $t_{b}$, was recorded for calculation purposes. Once burn-off locations were selected, the time elapsed between each resistor burn-off, $\Delta t_{b}$, can be readily calculated by taking the difference between resistor burn-off times. Since each resistor was located one sensor resolution, $R$, from the previous resistor, the instantaneous burning rate, $r(t)$, at the average of two sensor burnoff times is given by:

$$
r\left(\frac{t_{b, i}+t_{b, i+1}}{2}\right)=\frac{R}{\Delta t_{b}}
$$

Alternatively, the average regression rate for a motor firing can be calculated by replacing $\Delta \mathrm{t}_{\mathrm{b}}$ in Equation (9) with the average time elapsed between each resistor burnoff for the entire data set. The instantaneous burning rates calculated from the raw voltage data presented in Figure 17 are shown in Figure 18. This data reduction method has the advantage of producing instantaneous burning rates, but the calculated regression rates are not particularly accurate due to a high sensor resolution and significant signal noise which makes sensor burn-off data selection difficult. The accuracy of this method could be increased by reducing signal noise or by decreasing the sensor resolution. However, decreasing the sensor resolution yields less instantaneous regression data. Current sensor manufacturing and implementation methods yield a sensor resolution limit of approximately 0.01 inches. ${ }^{34}$ Furthermore, this method also has the potential to 
produce correlations of regression rate versus oxidizer mass flux with a single motor firing if the sensor can be precisely and accurately located at the initial combustion port surface, so that the combustion port diameter can be calculated throughout the motor burn.

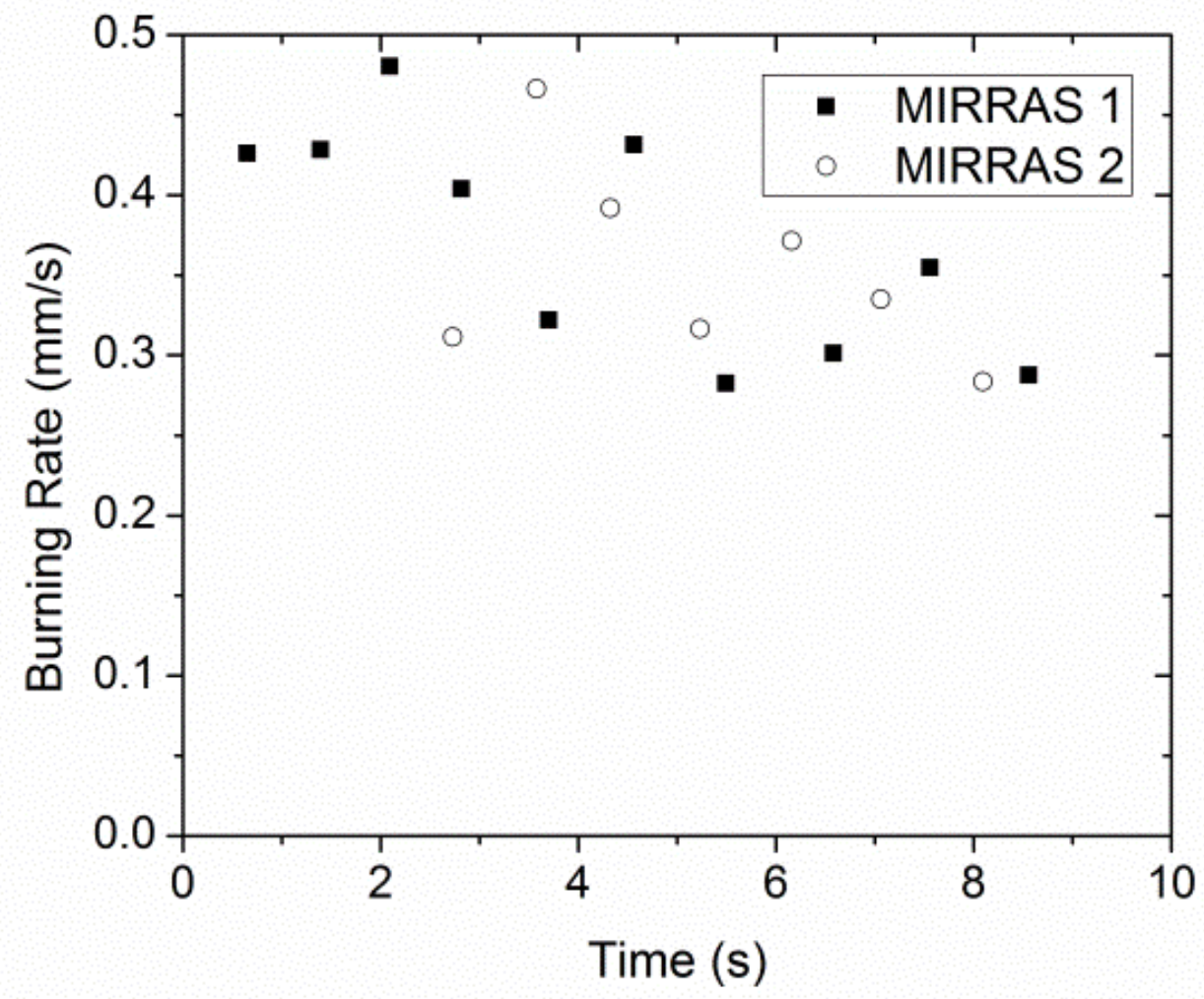

Figure 18. Instantaneous regression rate versus time data calculated from manual data point selection for two MIRRAS sensors embedded in a plain HTPB hybrid solid grain burning in gaseous oxygen at an average oxidizer mass flux of $1.65 \mathrm{~g} / \mathrm{cm}^{2}$-s.

In addition to the previously described linear approximation and manual data reduction methods, an attempt to apply a Fourier transform to the data sets was also 
made. In the FFT method, the voltage profile of a MIRRAS sensor was transformed and mapped to a neutral axis with a parabolic best fit approximation. The mapped data set was then transformed into the frequency domain to find the approximate resistor burnoff frequency, $f_{b}$. The average regression rate was then calculated by:

$$
r=R f_{b}
$$

Unfortunately, the FFT method produced regression rates that were inconsistent with those calculated by other methods, including the TOT method. In particular, regression rates calculated with this method were higher than those based on others methods by up to a factor of five. Several different mapping approximations were employed to attempt to resolve the discrepancy, but none were able to fully address the issue. Ultimately, it was concluded that signal noise was responsible for producing power frequencies that were higher than the true resistor burn-off frequency, thereby inflating the final regression rate calculations.

Regression rates calculated by the TOT method and with MIRRAS sensors are presented in Table 1 along with fuel mass-loss rates and average oxidizer mass fluxes for several plain and aluminized HTPB hybrid motors burned in gaseous oxygen. It should be noted that not all of the motors contained MIRRAS sensors. During the burning of motor $\mathrm{H} 8$, the squib igniter inhibited oxidizer flow and combustion of the solid fuel grain, so this data point was removed for analysis purposes. Several fuel mass loss rates and oxidizer to fuel ratios are not reported in Table 1 due to various problems encountered including motor casing rupture, combustion inhibition due to the squib igniter, and post-test motor burning with atmospheric air. 
Table 1. Average regression rates, mass-loss rates, oxidizer mass fluxes, and fuel-tooxidizer ratios for several burns of plain and aluminized HTPB hybrid motors in gaseous oxygen. Regression rates were calculated from traditional TOT methods and with regression sensors by implementing linear approximation and manual burn-off point selection techniques.

\begin{tabular}{|c|c|c|c|c|c|c|c|}
\hline \multirow{3}{*}{$\begin{array}{c}\text { Burn } \\
\text { Number }\end{array}$} & \multirow{3}{*}{ Fuel } & \multicolumn{3}{|c|}{ Regression Rate } & \multirow{3}{*}{$\begin{array}{c}\begin{array}{c}\text { Fuel Mass } \\
\text { Loss Rate }\end{array} \\
(\mathrm{kg} / \mathrm{s})\end{array}$} & \multirow{3}{*}{\begin{tabular}{|c|}
$\begin{array}{c}\text { Average } \\
\text { Oxidizer } \\
\text { Mass Flux }\end{array}$ \\
$\left(\mathrm{g} / \mathrm{cm}^{2}-\mathrm{s}\right)$ \\
\end{tabular}} & \multirow{3}{*}{$\begin{array}{c}\text { Oxidizer/ } \\
\text { Fuel } \\
\text { Ratio }\end{array}$} \\
\hline & & \multicolumn{3}{|c|}{$(\mathrm{mm} / \mathrm{s})$} & & & \\
\hline & & TOT & $\begin{array}{l}\text { MIRRAS } \\
\text { (Linear) }\end{array}$ & $\begin{array}{l}\text { MIRRAS } \\
\text { (Manual) }\end{array}$ & & & \\
\hline $\mathrm{H} 1$ & HTPB & 0.29 & - & - & 1.47 & 1.28 & 5.50 \\
\hline $\mathrm{H} 2$ & HTPB & 0.27 & 0.35 & 0.35 & 2.77 & 1.59 & 3.76 \\
\hline $\mathrm{H3}$ & HTPB & 0.30 & 0.34 & 0.38 & 3.49 & 2.82 & 5.30 \\
\hline $\mathrm{H} 4$ & HTPB & 0.37 & 0.38 & 0.37 & 5.10 & 2.62 & 3.36 \\
\hline $\mathrm{H} 5$ & HTPB & 0.63 & - & - & 2.70 & 6.67 & 4.73 \\
\hline $\mathrm{H} 6$ & HTPB & 0.82 & 0.85 & 0.82 & 5.92 & 9.35 & 3.60 \\
\hline $\mathrm{H} 7$ & HTPB & 0.98 & - & - & - & 10.75 & - \\
\hline $\mathrm{H} 8$ & HTPB & 0.49 & 0.31 & 0.31 & 0.67 & 11.38 & 6.23 \\
\hline $\mathrm{H9}$ & HTPB & 1.13 & - & - & - & 12.67 & - \\
\hline $\mathrm{A} 1$ & $\mathrm{HTPB}+5 \% \mathrm{Al}$ & 0.43 & 0.50 & 0.47 & 4.12 & 2.66 & 4.23 \\
\hline $\mathrm{A} 2$ & HTPB + 5\% Al & 0.46 & 0.44 & 0.49 & - & 2.83 & - \\
\hline A3 & $\mathrm{HTPB}+5 \% \mathrm{Al}$ & 0.81 & - & - & - & 5.47 & - \\
\hline
\end{tabular}

The regression rates calculated by each method are plotted against average oxidizer mass flux in Figure 19. The regression rates calculated by all methods agree closely with each other, but those calculated with MIRRAS data are inflated for most burns. This burning rate inflation is inherent in the calculation methods of the MIRRAS data due to signal noise. More explicitly, signal noise was prevalent in the voltage profiles of MIRRAS data sets, especially at the beginning and end of motor burns when stable combustion processes were not always achieved. This signal noise increased the 
slope of the best-fit linear approximation which resulted in an inflated burning rate value. The signal noise also made burn-off point selection very difficult in some cases, so that only a portion of the data set was able to be analyzed. When the end of a motor burn could not be included in the manual burn-off selection, the result was an inflated regression rate value.

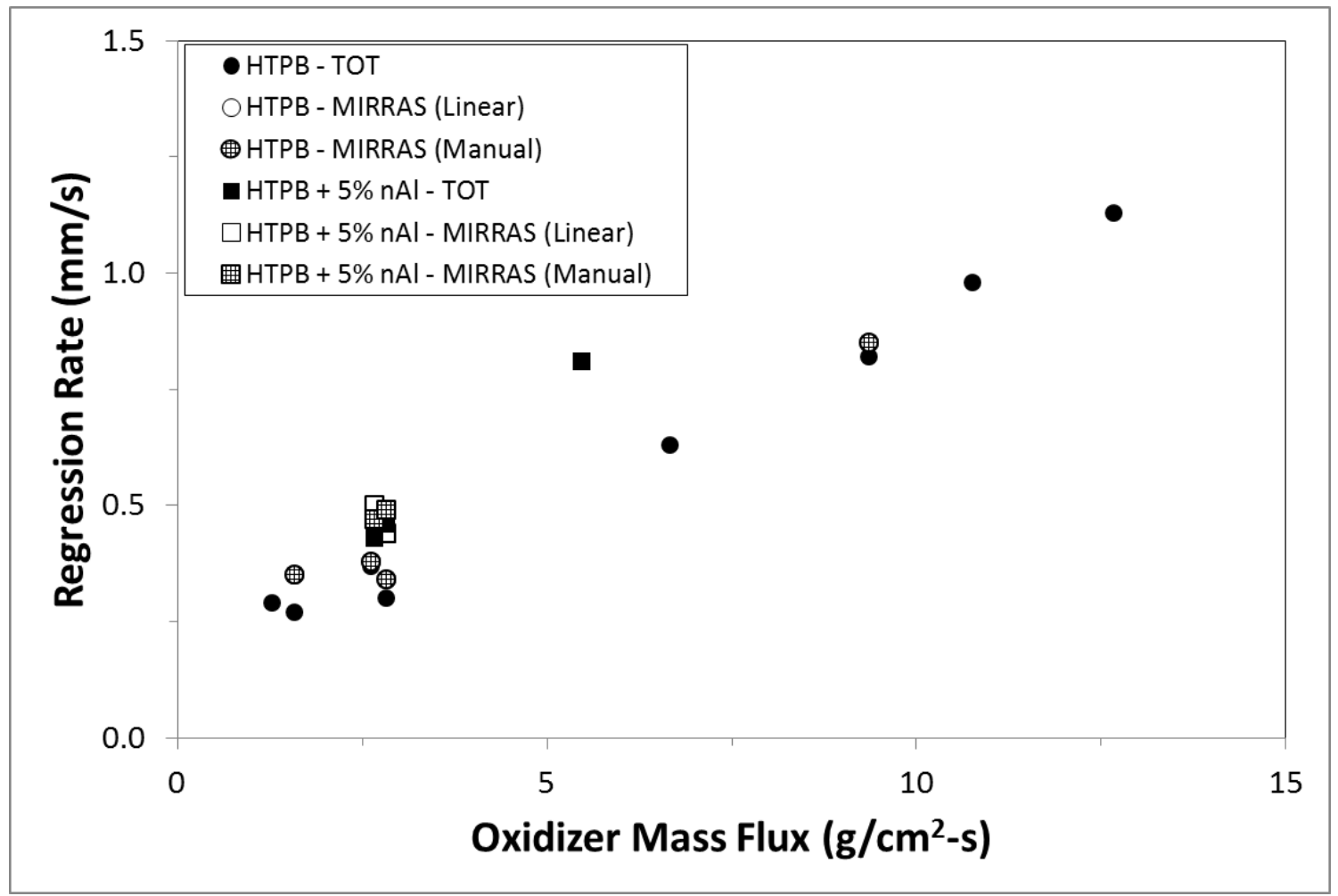

Figure 19. Average regression rates for several burns of plain and aluminized HTPB hybrid motors in gaseous oxygen, as a function of oxidizer mass flux. Regression rates were calculated from traditional TOT methods and with regression sensors by implementing linear approximation and manual burn-off point selection techniques.

The experimental data from these tests were compared to previous correlations from relevant literature to verify that the measured regression rates are reasonable. Table 
2 provides empirical constants for traditional power law regression rate correlations for plain and aluminized HTPB hybrid motors burning in gaseous oxygen from relevant literature. These correlations are plotted against experimental regression rate values calculated from the TOT method in Figure 20 on a standard plot and in Figure 21 on a $\log$-log plot. The differences in the literature correlations presented in Table 2, Figure 20and Figure 21 can be attributed to variable operating conditions, motor geometry, and motor formulations. The experimental regression rate values from these tests agree with the general trend of the literature correlations and fall within previously established regression rate values, which indicates the methods applied in this study are reasonable and comparable to established results. The experimental regression rate trend in Figure 20 begins to level off at the lowest oxidizer mass fluxes, which is typical of hybrid motors in the radiation heat transfer-dominated region. The experimental data show an increase in burning rate for motors containing 5\% nano-aluminum over their plain HTPB counterparts at all oxidizer mass fluxes tested, which is consistent with previous findings. This result confirms the enhancement of regression rates by the addition of aluminum particles and is attributed to enhanced radiation heat fluxes from the diffusion flame zone to the motor's regressing surface and the addition of an energetic fuel source near the surface. A traditional power law has been fitted to the plain and aluminized HTPB regression data, and the resultant empirical constants are presented in Table 2. 
Table 2. Empirical constants for traditional power law regression rate correlations of plain and aluminized hybrid HTPB motors burning in gaseous oxygen. Constants produce regression rate in $\mathrm{mm} / \mathrm{s}$.

\begin{tabular}{|c|c|c|c|c|}
\hline Fuel & $a$ & $n$ & Reference & $\begin{array}{c}\text { Oxidizer Mass Flux } \\
\text { Range }\left(\mathrm{g} / \mathrm{cm}^{2}-\mathrm{s}\right)\end{array}$ \\
\hline HTPB & 0.146 & 0.681 & Sutton 2010 & $3.8-30.2$ \\
\hline HTPB & 0.304 & 0.527 & Geroge et al. 2001 & $6.2-31.0$ \\
\hline HTPB & 0.240 & 0.647 & Evans et al. 2009 & $8-15$ \\
\hline HTPB & 0.202 & 0.732 & Present Study & $1.3-12.7$ \\
\hline HTPB+19.7\% Al (micro) & 0.117 & 0.956 & Geroge et al. 2001 & $5.1-23.0$ \\
\hline HTPB+13\% Al (nano-Alex) & 0.236 & 0.759 & Risha et al. 2002 & $8-15$ \\
\hline HTPB+13\% Al (nano-Flakes) & 0.343 & 0.596 & Evans et al. 2009 & $16.5-34.2$ \\
\hline HTPB+5\% Al (100 nm) & 0.185 & 0.870 & Present Study & $2.7-5.5$ \\
\hline
\end{tabular}

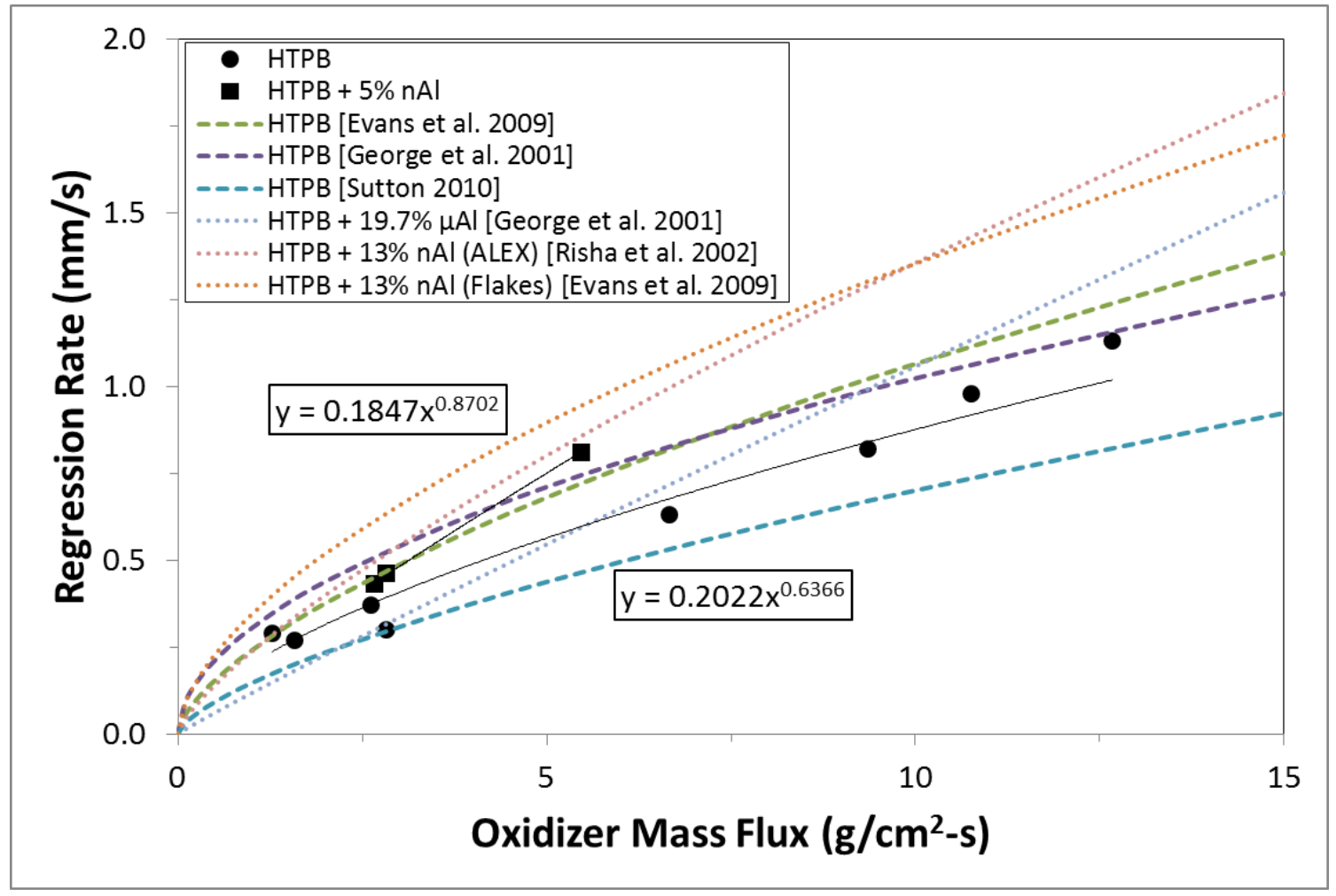

Figure 20. Literature correlations of regression rate and experimental TOT method regression rates of plain and aluminized hybrid HTPB motors burning in gaseous oxygen on a standard plot. 


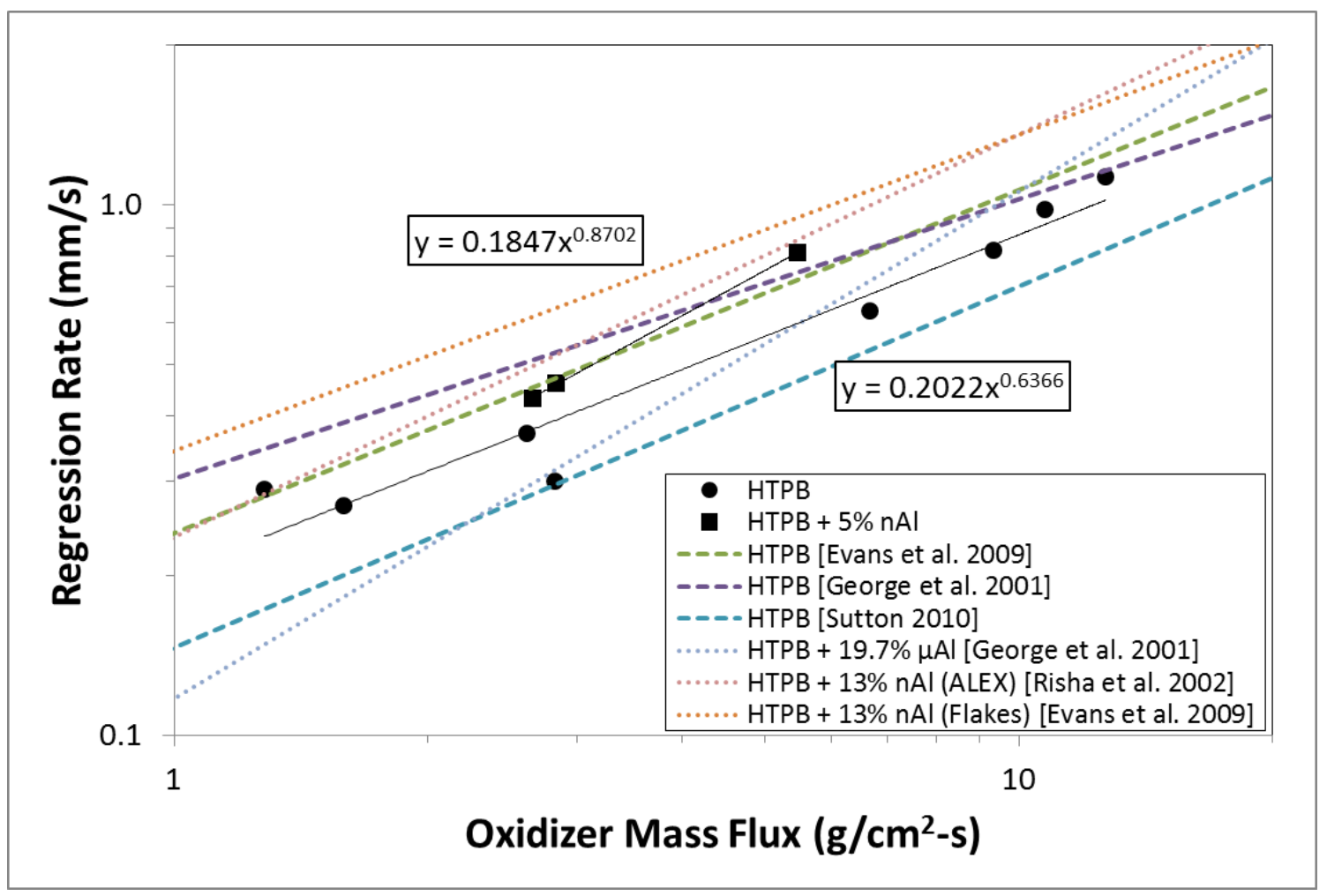

Figure 21. Literature correlations of regression rate versus oxidizer mass flux and experimental TOT method regression rates of plain and aluminized hybrid HTPB motors burning in gaseous oxygen on a log-log plot.

Table 3 provides empirical constants for traditional power law mass-loss rate correlations for plain and aluminized HTPB hybrid motors burning in gaseous oxygen from relevant literature. These correlations are plotted against experimental mass-loss rate values for lower oxidizer mass fluxes in Figure 22. Similar to the regression rate data, the mass-loss rate data closely agree with literature correlations. Literature correlations suggest an increase in mass-loss rate can be seen for aluminized formulations at higher oxidizer mass fluxes, but further testing of aluminized formulations is necessary to confirm this trend. 
Table 3. Empirical constants for traditional power law mass-loss rate correlations of plain and aluminized hybrid HTPB motors burning in gaseous oxygen. Constants produce mass-loss rate in $\mathrm{kg} / \mathrm{s}$.

\begin{tabular}{|c|c|c|c|c|}
\hline Fuel & $b$ & $m$ & Reference & $\begin{array}{c}\text { Oxidizer Mass Flux } \\
\text { Range }\left(\mathrm{g} / \mathrm{cm}^{2}-\mathrm{s}\right)\end{array}$ \\
\hline HTPB & $3.38 \times 10^{-3}$ & 0.629 & Risha et al. 2002 & $9-15$ \\
\hline HTPB+13\% Al (nano-Alex) & $1.33 \times 10^{-3}$ & 1.178 & Risha et al. 2002 & $8-15$ \\
\hline
\end{tabular}

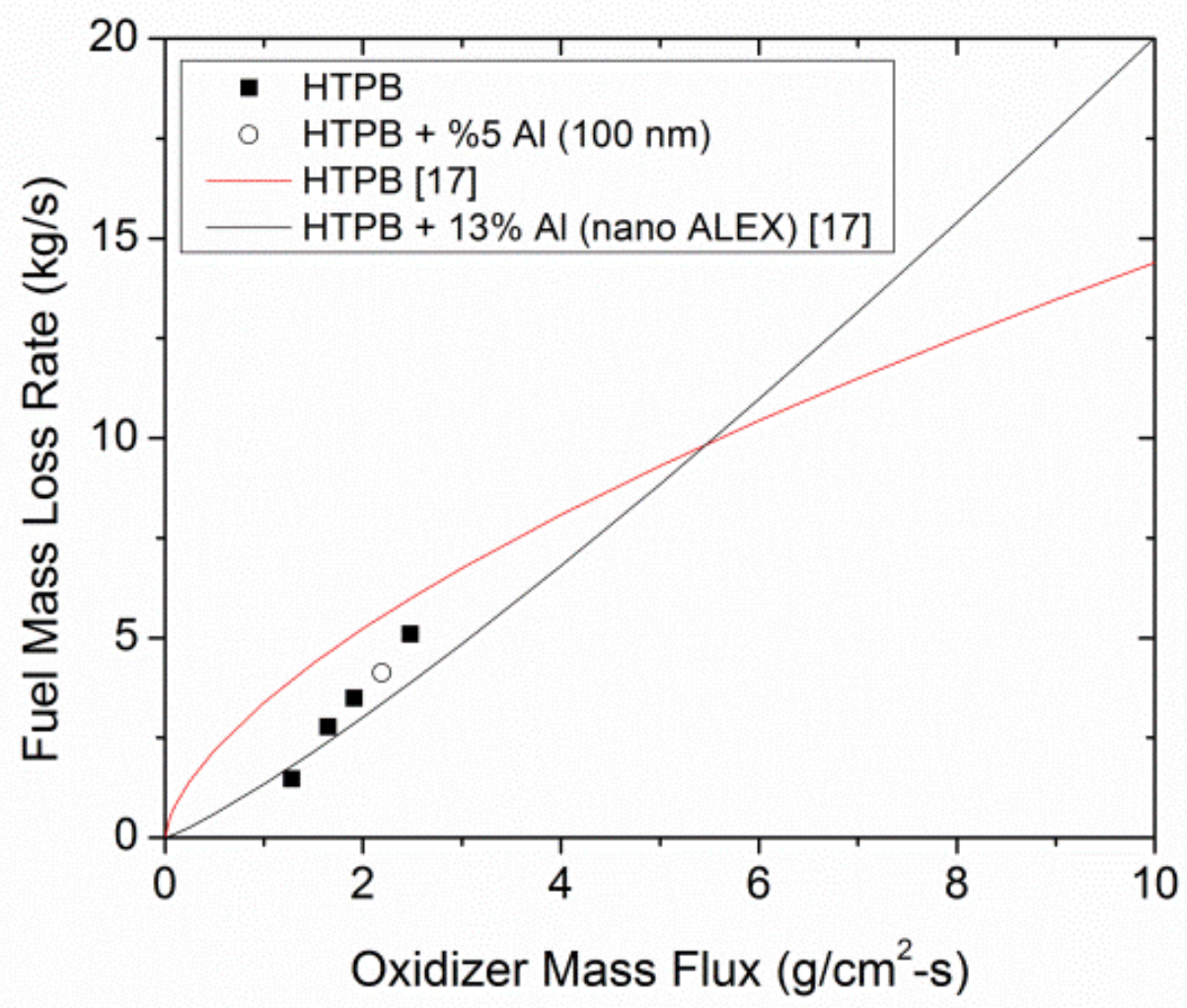

Figure 22. Literature correlations of mass-loss rate versus oxidizer mass flux and experimental mass-loss rates of plain and aluminized hybrid HTPB motors burning in gaseous oxygen. 


\section{CONCLUSIONS AND FUTURE WORK}

Energetic commercial and novel aluminum nano-particles have been characterized to better understand their properties and effects on combustion behavior of hybrid rocket motors. Procedures were successfully developed for manufacturing plain HTPB and commercially aluminized hybrid motors. Extensive testing has been completed to develop similar procedures for motors containing novel aluminum particles, but further work is necessary to produce acceptable solid fuel grains with this additive. The addition on DOA plasticizer and/or the removal of a residual chemical compound in the novel mixture may serve to solve the curing problems associated with these mixtures.

The implementation of TOT and regression sensor methods for determining the hybrid motor burning rates was successful and served to validate the use of the described lab-scale burner for regression rate determination. The data and correlations obtained through experimentation will serve as baselines for comparison in future testing.

The application of several data reduction methods to MIRRAS sensor data showed the sensors are relatively accurate and can be successfully used to measure hybrid motor regression rates. Furthermore, MIRRAS sensors exhibited the unique capability of relaying instantaneous burning rate with minimal necessary equipment. Further iteration of MIRRAS sensor design and implementation procedures could lead to the determination of a regression rate power law correlation over a wide oxidizer mass flux range in a single hybrid motor test. 
The commercial, energetic nano-aluminum additive increases the HTPB hybrid motor's fuel regression rate at all tested oxidizer mass fluxes through enhanced radiation heat transfer. Advanced synthesis techniques designed to further reduce the fundamental particle size and ignition energy of the nano-aluminum have been developed and will be used to manufacture novel aluminized HTPB hybrid motors. Burn rate testing on these motors will serve to evaluate the effectiveness of the new additive synthesis method in hybrid rockets. 


\section{REFERENCES}

${ }^{1}$ Sutton, G. P., Biblarz, O., Rocket Propulsion Elements, $8^{\text {th }}$ ed., Wiley, New York, 2010.

${ }^{2}$ Karabeyoglu, M. A., Altman, D., and Cantwell, B. J., “Combustion of Liquefying Hybrid Propellants: Part 1. General Theory," Journal of Propulsion and Power, Vol. 18, No. 3, 2002, pp. 610-620.

${ }^{3}$ Karabeyoglu, M.A., and Cantwell, B. J., "Combustion of Liquefying Hybrid Propellants: Part 2. Stability of Liquid Films," Journal of Propulsion and Power, Vol. 18, No. 3, 2002, pp. 621-630.

${ }^{4}$ DeSain, J. D., Curtiss, T. J., Metzler, K. M., Brady, B. B., “Testing Hypergolic Ignition of Paraffin Wax/LiAlH4 Mixtures," AIAA Joint Propulsion Conference, AIAA 2010-6636, Washington, DC, 2010.

${ }^{5}$ Paravan, C., Reina, A., Sossi, A., Manzoni, M., Massini, G., Rambaldi, G., Duranti, E., Adami, A., Seletti, E., and DeLuca, L. T., “Time-Resolved Regression Rate of Innovative Hybrid Solid Fuel Formulations," Progress in Propulsion Physics, Vol. 4, 2013, pp. 75-98.

${ }^{6}$ Risha, G. A., Evans, B. J., Boyer, E., and Kuo, K. K., "Metals, Energetic Additives and Special Binders Used in Solid Fuels for Hybrid Rockets," Fundamentals of Hybrid Rocket Combustion and Propulsion, edited by M. J. Chiaverini and K. K. Kuo, Progress in Astronautics and Aeronautics, AIAA, Reston, VA, 2007, pp. 413-456. 
${ }^{7}$ Kim, S., Lee, J., Moon, H., Sung, H., Kim, J., and Cho, J., "Effect of Paraffin- LDPE Blended Fuel on the Hybrid Rocket Motor," AIAA Joint Propulsion Conference, AIAA 2010-7031, Washington, DC, 2010.

${ }^{8}$ George, P., Krishnan, S., Varkey, P. M., Ravindran, M., and Ramachandran, L., "Fuel Regression Rate in Hydroxyl-Terminated-Polybutadiene/Gaseous-Oxygen Hybrid Rocket Motors," Journal of Propulsion and Power, Vol.17, No. 1, 2001, pp. 35-42.

${ }^{9}$ Pastrone, D., “Approaches to Low Fuel Regression Rate in Hybrid Rocket Engines,” International Journal of Aerospace Engineering, Vol. 2012, 2012.

${ }^{10}$ Shin, H., Lee, C., and Chang, S. Y., "The Enhancement of Regression Rate of Hybrid Rocket Fuel by Various Methods," AIAA Aerospace Sciences Meeting, AIAA 2005-0359, Washington, DC, 2005.

${ }^{11}$ Lee, C., Na, Y., and Lee, G., "The Enhancement of Regression Rate of Hybrid Rocket Fuel by Helical Grain Configuration and Swirl Flow," AIAA Joint Propulsion Conference, AIAA 2005-3906, Washington, DC, 2005.

${ }^{12}$ Lewin, A., Dennis, J., Conley, B., and Suzuki, D., "Experimental Determination of Performance Parameters for a Polybutadiene/Oxygen Hybrid Rocket," AIAA Joint Propulsion Conference, AIAA 1992-3590, Washington, DC, 1992.

${ }^{13}$ Chiaverini, M. J., "Review of Solid Fuel Regression Rate Behavior in Classical and Nonclassical Hybrid Rocket Motors," Fundamentals of Hybrid Rocket Combustion and Propulsion, edited by M. J. Chiaverini and K. K. Kuo, Progress in Astronautics and Aeronautics, AIAA, Reston, VA, 2007, pp. 37-126. 
${ }^{14}$ Frederick, R. A., Whitehead, J. J., Knox, L. R., and Moser, M. D., "Regression Rates Study of Mixed Hybrid Propellants," Journal of Propulsion and Power, Vol. 23, No. 1, 2007, pp. 175-180.

${ }^{15}$ Ramohalli, K., Bates, R., Jones, M., Wygle, B., and Yi, J., "Some Recent Results from a Program in Hybrids at the University of Arizona," AIAA Joint Propulsion Conference, AIAA 1995-2945, Washington, DC, 1995.

${ }^{16}$ Evans, B., Favorito, N. A., Boyer, E., Risha, G. A., Wehrman, R. B., and Kuo, K. K., “Characterization of Nano-Sized Energetic Particle Enhancement of Solid-Fuel Burning Rates in an X-Ray Transparent Hybrid Rocket Engine," AIAA Joint Propulsion Conference, AIAA 2004-3821, Washington, DC, 2004.

${ }^{17}$ Risha, G., Boyer, E., Wehrman, R., and Kuo, K., "Performance Comparison of HTPBBased Solid Fuels Containing Nano-Sized Energetic Powder in a Cylindrical Hybrid Rocket Motor," AIAA Joint Propulsion Conference, AIAA 2002-3576, Washington, DC, 2002.

${ }^{18}$ Evans, B., Boyer, E., Kuo, K., Risha, G., and Chiaverini, M., "Hybrid Rocket Investigations at Penn State University’s High Pressure Combustion Laboratory: Overview and Recent Results," AIAA Joint Propulsion Conference, AIAA 20095349, Washington, DC, 2009.

${ }^{19}$ Strand, L. D., Ray, R. L., and Cohen, N. S., "Hybrid Rocket Combustion Study," AIAA Joint Propulsion Conference, AIAA 1993-2412, Washington, DC, 1993. 
${ }^{20}$ Stephens, M., Sammet, T., Petersen, E. L., Carro, R., Wolf, S., and Smith, C., "Performance of Ammonium-Perchlorate-Based Composite Propellant Containing Nanoscale Aluminum," Journal of Propulsion and Power, Vol. 26, No. 3, 2010, pp. 461-466.

${ }^{21}$ Allen, T. W., Demko, A. R., Johnson, M., Sammet, T., Petersen, E. L., Reid, D. L., Draper, R., and Seal, S., "Laboratory-Scale Burning of Composite Solid Propellant for Studying Novel Nano-particle Synthesis Methods," AIAA Aerospace Sciences Meeting, AIAA 2013-0821, Washington, DC, 2013.

${ }^{22}$ Kreitz, K., Petersen, E. L., Reid, D., and Seal, S., “Scale-Up Effects of Nano-particle Production on the Burning Rate of Composite Propellant," Combustion Science and Technology, Vol. 184, No. 6, 2012, pp. 750-766.

${ }^{23}$ Jayaraman, K., Anand, K. V., Bhatt, D. S., Chakravarthy, S. R., and Sarathi, R., "Production, Characterization, and Combustion of Nanoaluminum in Composite Solid Propellants," Journal of Propulsion and Power, Vol. 25, No. 2, 2009, pp. 471-481.

${ }^{24}$ DeLuca, L. T., Galfetti, L., Severini, F., Meda, L., Marra, G., Vorozhtsov, A. B., Sedoi, V. S., and Babuk, V. A., "Burning of Nano-Aluminized Composite Rocket Propellants," Combustion, Explosion, and Shock Waves, Vol. 41, No. 6, 2005, pp. 680-692. 
${ }^{25}$ Marxman, G. A., and Wooldridge, C. E., "Research on the Combustion Mechanism of Hybrid Rockets," Advances in Tactical Rocket Propulsion, edited by S. S. Penner, AGARD Conference Proceedings, Technivision Services, London, 1968, pp. 421-477.

${ }^{26}$ Marxman, G. A., and Gilbert, M., "Turbulent Boundary Layer Combustion in the Hybrid Rocket," Symposium (International) on Combustion, Vol. 9, No. 1, Academic Press, Inc., New York, New York, 1963, pp. 371-383.

${ }^{27}$ Marxman, G. A., "Boundary Layer Combustion in Propulsion," Symposium (International) on Combustion, Vol. 11, No. 1, Academic Press, Inc., New York, New York, 1967, pp. 269-289.

${ }^{28}$ Smoot, L. D., and Price, C. F., "Regression Rates of Nonmetalized Hybrid Fuel Systems," AIAA Journal, Vol. 3, No. 8, 1965, pp. 1408-1413.

${ }^{29}$ Chiaverini, M. J., Harting, G. C., Lu, Y., Kuo, K. K., Serin, N., and Johnson, D. K., "Fuel Decomposition and Boundary-Layer Combustion Processes of Hybrid Rocket Motors,"," AIAA Joint Propulsion Conference, AIAA 1995-2686, Washington, DC, 1995.

${ }^{30}$ Houser, T. J., and Peck, M. V., "Research in Hybrid Combustion," Heterogeneous Combustion. edited by H. G. Wolfhard, I. Glassman, and L. Green, Jr., Progress in Astronautics and Aeronautics, AIAA, New York, NY, 1964. 
${ }^{31}$ Cauty, F., Seryn, N., and Gramer, D., "Solid-Fuel Pyrolysis Phenomena and Regression Rate, Part 2: Measurement Techniques," Fundamentals of Hybrid Rocket Combustion and Propulsion, edited by M. J. Chiaverini and K. K. Kuo, Progress in Astronautics and Aeronautics, AIAA, Reston, VA, 2007, pp. 167206.

${ }^{32}$ DeLuca, L.T., Galfetti, L., Bosisio, F., Raina, H., Colombo, A., and Colombo, G., “A Hybrid Microcombustor for Regression Rate Measurements," International Astronautical Congress Proceedings, IAC-06-C4.2.01, 2006.

${ }^{33}$ Chiaverini, M. J., Serin, N., Johnson, D. K., Lu, Y., Kuo, K. K., and Risha, G. A., "Regression Rate Behavior of Hybrid Rocket Solid Fuels," Journal of Propulsion and Power, Vol. 16, No. 1, 2000, pp. 125-132.

${ }^{34}$ De Zilwa, S., Zilliac, G., Reinath, M., and Karabeyoglu, A., "Time-Resolved FuelGrain Port Diameter Measurement in Hybrid Rockets," Journal of Propulsion and Power, Vol. 20, No. 4, 2004, pp. 684-689.

${ }^{35}$ Stromberg, G. F. and Easton, J. F., Active Propellant Grain Regression Rate Monitor for Rocket Engines, Patent 3553577, 5 Jan. 1971. Print.

${ }^{36}$ Monti, R. and Mazzola, M., “Continuous Regression Rate Measurement in Hybrid Rockets," AIAA $14^{\text {th }}$ Aerospace Sciences Meeting, AIAA 76-104, Washington, DC, 1976.

${ }^{37}$ Gramer, D. J., and Taagen, J. T., "Low-Cost Surface Regression Sensor for Hybrid Fuels, Solid Propellant, and Ablatives," AIAA Joint Propulsion Conference, AIAA 2001-3529, Washington, DC, 2001. 
${ }^{38}$ Hocaoglu, O., Ozbelge, T., Pekel, F., and Ozkar, S., "Fine-Tuning the Mechanical Properties of Hydroxyl-Terminate Polybutadiene/Ammonium Perchlorate-Based Composite Solid Propellants by Varying the NCO/OH and Trio/Diol Ratios," Journal of Applied Polymer Science, Vol. 84, No. 11, 2002, pp. 2072-2079.

${ }^{39}$ Manjari, R., Somasundaran, U. I., Joseph, V. C., and Sriram, T., "Structure-Property Realtionship of HTPB-Based Propellants. II. Formulation Tailoring for Better Mechanical Properties," Journal of Applied Polymer Science, Vol. 48, No. 2, 1991, pp. 279-289.

${ }^{40}$ Callister, W. D., Jr., and Rethwisch, D. G., Materials Science and Engineering: An Introduction, $8^{\text {th }}$ ed., Wiley, Hoboken, NJ, 2010, Chap. 18. 